\title{
Future projections of Mediterranean cyclone characteristics using the Med-CORDEX ensemble of coupled regional climate system models
}

\author{
Marco Reale ${ }^{1,2}$ (1) . William David Cabos Narvaez ${ }^{3}$. Leone Cavicchia ${ }^{4}$. Dario Conte ${ }^{5}$. Erika Coppola ${ }^{2}$. \\ Emmanouil Flaounas $^{6}$ - Filippo Giorgi ${ }^{2} \cdot$ Silvio Gualdi $^{5}$. Assaf Hochman ${ }^{7,15} \cdot$ Laurent Li $^{8} \cdot$ Piero Lionello $^{9,5}$. \\ Zorica Podrascanin $^{10}$ - Stefano Salon ${ }^{1}$ - Emilia Sanchez-Gomez ${ }^{11}$ - Enrico Scoccimarro ${ }^{5}$. Dmitry V. Sein ${ }^{12,13}$. \\ Samuel Somot ${ }^{14}$
}

Received: 13 May 2021 / Accepted: 19 October 2021 / Published online: 3 November 2021

(c) The Author(s) 2021

\begin{abstract}
Here, we analyze future projections of cyclone activity in the Mediterranean region at the end of the twenty-first century based on an ensemble of state-of-the-art fully-coupled Regional Climate System Models (RCSMs) from the Med-CORDEX initiative under the Representative Concentration Pathway (RCP) 8.5. Despite some noticeable biases, all the RCSMs capture spatial patterns and cyclone activity key characteristics in the region and thus all of them can be considered as plausible representations of the future evolution of Mediterranean cyclones. In general, the RCSMs show at the end of the twenty-first century a decrease in the number and an overall weakening of cyclones moving across the Mediterranean. Five out of seven RCSMs simulate also a decrease of the mean size of the systems. Moreover, in agreement with what already observed in CMIP5 projections for the area, the models suggest an increase in the Central part of the Mediterranean region and a decrease in the South-eastern part of the region in the cyclone-related wind speed and precipitation rate. These rather two opposite tendencies observed in the precipitation should compensate and amplify, respectively, the effect of the overall reduction of the frequency of cyclones on the water budget over the Central and South-eastern part of the region. A pronounced inter-model spread among the RCSMs emerges for the projected changes in the cyclone adjusted deepening rate, seasonal cycle occurrence and associated precipitation and wind patterns over some areas of the basin such as Ionian Sea and Iberian Peninsula. The differences observed appear to be determined by the driving Global Circulation Model (GCM) and influenced by the RCSM physics and internal variability. These results point to the importance of (1) better characterizing the range of plausible futures by relying on ensembles of models that explore well the existing diversity of GCMs and RCSMs as well as the climate natural variability and (2) better understanding the driving mechanisms of the future evolution of Mediterranean cyclones properties.
\end{abstract}

Keywords Mediterranean region $\cdot$ Med-CORDEX $\cdot$ Coupled regional climate system models $\cdot$ Cyclones $\cdot$ Climate change

\section{Introduction}

The Mediterranean region is located at mid-latitudes and includes the continental Southern Europe, Northern Africa and the Middle East, all surrounding the Mediterranean Sea (Fig. 1). The presence of this relatively large water mass acts as a source of moisture and heat to atmospheric weather

Marco Reale

mreale@inogs.it; reale.marco82@gmail.com

Extended author information available on the last page of the article systems. Furthermore, it imposes sharp land-sea transitions that strongly affect both atmospheric and oceanic dynamics over the region (see Lionello et al. 2006, 2012; Ulbrich et al. 2012; Flaounas et al. 2021b; Hochman et al. 2021).

Extra-tropical cyclones play a fundamental role in shaping the weather of the Mediterranean region (Fig. 1, Lionello et al. 2006; Nissen et al. 2010; Ulbrich et al. 2012; Lionello et al. 2012; Flaounas et al. 2013; Reale and Lionello 2013; Lionello et al. 2016 and references inside; Flaounas et al. 2017; Flaounas et al. 2021b). The location and complex orography of the region allow the development of different cyclonic systems with a marked seasonal cycle. These 


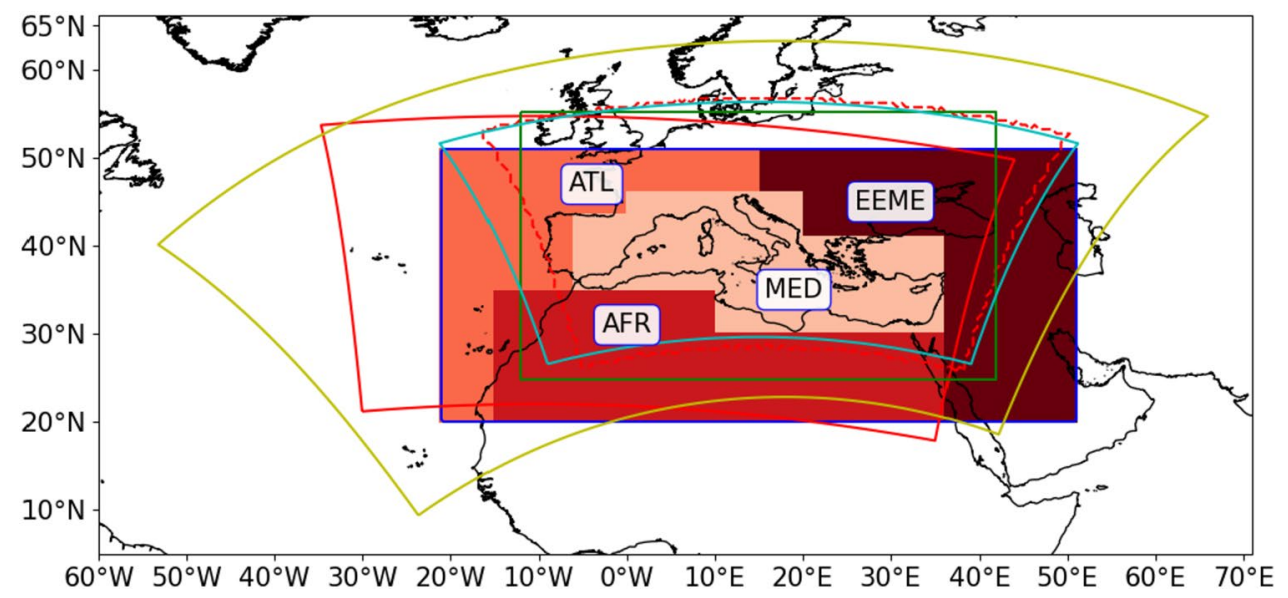

Fig. 1 The Mediterranean region (blue line) and sub-areas identified for the cyclogenesis processes, AFR (Northern Africa), MED (Mediterranean), ATL (North Atlantic), EEME (Eastern Europe/ Middle East). Original atmospheric domains of the models (Table 1)

include for example: lee cyclones, which occur mostly in winter at the lee of the Alps, Atlas Mountains and Pyrenees, or thermal lows which usually occur in summer (Trigo et al. 1999; Trigo 2006; Lionello et al. 2002; Lionello et al. 2016 and references inside; Flaounas et al. 2018; Flaounas et al. 2021b).

Cyclogenesis in the region has been shown to be driven by the intrusion of upper-tropospheric systems. These result from Rossby wave breaking over the Atlantic Ocean with an active role played by deep convection close to the cyclone center. Deep convection acts as a source of potential vorticity for the cyclone (see Flaounas et al. 2021a, b). Past studies have identified several cyclogenetic areas in the region: the Atlas Mountains, the Gulf of Genoa, the Aegean Sea, the Iberian peninsula, the Black Sea and the Eastern Mediterranean (Alpert et al. 1990; Trigo et al. 1999; Lionello et al. 2006, 2016; Campins et al. 2010; Flaounas et al. 2018, 2021 b; Buzzi et al. 2020). Moreover, approximately $11 \%$ of cyclones moving across the region originate in the Atlantic Ocean (Lionello et al. 2016). Mediterranean systems are generally shallower, slower, smaller and less persistent with respect to other mid-latitude cyclones (Lionello et al. 2016).

Cyclone activity in the Mediterranean has important effects on the hydrological cycle and the distribution of the precipitation in the region (Flaounas et al. 2016, 2017). Furthermore, some cyclones are also associated with detrimental extreme events, such as heavy precipitation, windstorms, storm surges and marine storminess (Lionello et al. 2006, 2012; Nissen et al. 2010; Liberato et al. 2011; Reale and Lionello 2013; Flaounas et al. 2017; Lionello et al. 2019; Lionello et al. 2020; Flaounas et al. 2021b).

Several studies have focused on characterizing Mediterranean cyclone activity in past and present periods using are shown: ROM (red line), EBUPOM2c (red dashed line), CNRMRCSM4 (cyan line), LMDZ4NEMOMED8 (green line), COSMOMED (yellow line). The part of the ERA5 global domain covering the Mediterranean region is shown in blue line

observations, reanalyses, global and/or regional climate models (Trigo et al. 1999; Maheras et al. 2001; Trigo 2006; Lionello et al. 2002, 2016; Flaounas et al. 2018). Others have focused on the future projections of cyclonic activity over the region (Somot 2005; Lionello and Giorgi 2007; Raible et al. 2010; Cavicchia et al. 2014; Nissen et al. 2014; Zappa et al. 2015; Hochman et al. 2018a, b, 2020). For example, Lionello and Giorgi (2007) have demonstrated weaker (stronger) cyclone activity and a decrease (increase) in precipitation over the Eastern (North-Western) Mediterranean for the end of the twenty-first century under SRES emission scenarios A2 and B2. On the other hand, Raible et al. (2010) found in the ECHAM GCM a decrease in cyclone activity over the Western Mediterranean by the end of the century, no significant change in the Eastern Mediterranean and a slight decrease in cyclone intensity for the entire region. Nissen et al. (2014) using a suite of 7 simulations of two coupled GCMs (CMCC-CM and ECHAM5MPIOM) under different emissions scenarios showed a decrease in the number of cyclones crossing the region and associated windstorms. Zappa et al. (2015) analyzed a suite of 17 CMIP5 models under Representative Concentration Pathway (RCP) 8.5 emission scenario and found an overall reduction of cyclone number in the period 2082-2099 (with respect to 1976-2005) over the Mediterranean region, with a concomitant increase of the associated precipitation over the western part of the Mediterranean basin. Finally, Hochman et al. (2018a, 2020) have found a significant decrease in Eastern Mediterranean cyclone frequency $(-35 \%)$ and associated daily precipitation (-26\%) using 8 CMIP5 models for the end of the twenty-first century under RCP8.5.

There is no general consensus regarding the effect of global warming on cyclone activity over the Mediterranean 
basin. Moreover, previous studies were based on a single or an ensemble of low resolution uncoupled/coupled GCMs (ECHAM5 and CMIP5) or single uncoupled regional climate model. This: (i) poses some limitations on the representation of cyclone activity in the region which has been shown to be influenced by the model resolution and the frequency of the atmosphere and ocean coupling (Akhtar et al. 2014; Flaounas et al. 2018; Gaertner et al. 2018), (ii) leads to omit the various sources of uncertainty related for example to the choice of the regional climate models, driving GCM and natural variability. Additionally, all the previous studies have been focused on the analysis of the changes in the spatial distribution of cyclones and related precipitation, without considering changes in the cyclones' features such as size, depth or deepening rate. Since cyclones play a fundamental role in the dynamics of extreme weather in the Mediterranean it is important to consider changes in the features of systems crossing the region and to address the sources of uncertainties affecting the projections in the area by considering different possible climate futures through a multi-model approach.

In recent years the Med-CORDEX initiative (Ruti et al. 2016; Somot et al. 2018; www.medcordex.eu) has been launched to develop fully-coupled Regional Climate System Models (RCSMs) for the Mediterranean basin under the framework of the Coordinated Regional Downscaling EXperiment (CORDEX, Giorgi et al. 2009). More specifically, the Med-CORDEX RCSMs include a high-frequency coupling of the ocean and atmosphere components (6 min-1 day), both represented at relatively high-resolution (25-50 km for the atmosphere, 6-20 km for the ocean). One of the main aims of this initiative is to use these coupled models to produce coordinated high-resolution ensembles of climate projections for the Mediterranean basin. An initial ensemble has already been generated including seven simulation runs performed with 5 different RCSMs driven by GCM projections from the Coupled Model Intercomparison Project Phase 5 (CMIP5, Taylor et al. 2012) under RCP 8.5 emission scenario, considered as the high end (see Darmaraki et al. 2019 for description and a first use of this ensemble).

In this study we use this ensemble to revisit the still open question concerning the response of Mediterranean cyclone activity to global warming. Our focus is on a variety of cyclone characteristics, such as frequency, intensity, track, associated precipitation yield and wind speed. Particularly, their changes by the end of the twenty-first century are compared to historical reference values. Moreover, we discuss the sources of uncertainties affecting the projections in the region with special attention dedicated to the driving GCM and RCSM setup and internal features.

The paper is organized as follows: Sect. 2 describes the main characteristics of the models, our approach for detecting and tracking Mediterranean cyclones and the procedure adopted to associate precipitation and wind patterns to each system. Section 3 presents an assessment of the ability of RCSMs to reproduce the main observed characteristics of Mediterranean cyclones and related precipitation and wind patterns for present climate conditions, along with an analysis of future projections of cyclone activity in response to increased greenhouse gas concentrations. Section 4 discusses the possible sources of the differences observed among RCSMs projections while Sect. 5 presents our conclusions and the possible future research avenues.

\section{Data and methods}

\subsection{ERA5 reanalysis and Med-CORDEX models}

We analyze cyclone activity in the Mediterranean region (Fig. 1) using a set of 7 RCSM simulations produced as part of the Med-CORDEX initiative (Ruti et al. 2016; www. medcordex.eu) and the ERA5 reanalysis (Hersbach et al. 2020) as reference dataset. The variables considered here are the mean sea level pressure (MSLP), precipitation and wind fields. ERA5 is used for the sake of consistency, since it is also employed for evaluating cyclone activity. The simulations are based on 5 different coupled RCSMs (ROM, EBUPOM2c, CNRM-RCSM4, LMDZ4NEMOMED8 and COSMOMED) driven by five different GCMs (MPI-ESMLR, MPI-ESM-MR, CNRM-CM5, IPSL-CM5A-MR and CMCC-CM), being part of CMIP5 (Table 1). One interesting new feature of this ensemble is represented by the relatively high-resolution of the oceanic (eddy-resolving) and atmospheric components as well as the high coupling frequency between the two. The representation of the air-sea exchanges through this high-resolution interface represents a clear advantage for the representation of cyclone dynamics in the region, which is influenced by ocean-atmosphere interactions (Flaounas et al. 2021a).

CMIP5 GCM models have been shown to be able to generate a Mediterranean storm track and to reasonably represent the observed precipitation, evaporation, moisture fluxes and wind patterns in the region (e.g. Kelley et al. 2012; Seager et al. 2014; Nissen et al. 2014; Zappa et al. 2015).

All the RCSMs are driven by the respective GCM for a historical period (1950-2005) and for a future period (2006-2100) under emission scenario RCP8.5 (Taylor et al. 2012). The ensemble of simulations we consider consists of the GCM/RCSM combinations shown in Table 1: the LMDZ4NEMOMED8 RCSM (hereafter referred to LMD-MPI, LMD-CNRM and LMD-IPSL) driven by three different GCMs (MPI-ESM-MR, CNRM-CM5, IPSL-CM5A-MR), the CNRM-RCSM4 RCSM driven by the CNRM-CM5 GCM (hereafter CNRM-RCSM4), ROM 
Table 1 Characteristics of the Med-Cordex regional coupled models (RCSMs)

\begin{tabular}{|c|c|c|c|c|c|c|c|c|c|}
\hline Short Name & RCSMs & Institute & $\begin{array}{l}\text { Driving } \\
\text { GCM }\end{array}$ & $\begin{array}{l}\text { ATM } \\
\text { model }\end{array}$ & Ocean model & $\begin{array}{l}\text { Hor Atm } \\
\text { RES }\end{array}$ & Oce RES & $\begin{array}{l}\text { Coupling } \\
\text { frequency }\end{array}$ & I/BC and spin-up \\
\hline ROM & $\begin{array}{l}\text { ROM } \\
\text { (Sein et al. } \\
\text { 2015) }\end{array}$ & $\begin{array}{l}\text { AWI/GER- } \\
\text { ICS }\end{array}$ & \multirow{2}{*}{$\begin{array}{l}\text { MPI-ESM- } \\
\text { LR } \\
\text { (Giorgetta } \\
\text { et al. } \\
\text { 2013) }\end{array}$} & REMO & MPIOM & $25 \mathrm{~km}$ & $\begin{array}{l}5-20 \mathrm{~km} \\
40 \mathrm{z}-\mathrm{lev}\end{array}$ & $180 \mathrm{~min}$ & $\begin{array}{l}\text { PHC } 180 \\
\quad \text { (ocean) }+64(\text { cou- } \\
\text { pled) years }\end{array}$ \\
\hline EBU-POM & $\begin{array}{l}\text { EBUPOM2c } \\
\text { (Djurdjevic } \\
\text { and Rajko- } \\
\text { vic, 2008) }\end{array}$ & $\begin{array}{l}\text { University } \\
\text { of Bel- } \\
\text { grade }\end{array}$ & & ETA & POM & $50 \mathrm{~km}$ & $\begin{array}{l}50 \mathrm{~km} \\
21 \mathrm{z}-\mathrm{lev}\end{array}$ & $6 \min$ & MEDAR 5 years \\
\hline LMD-MPI & $\begin{array}{l}\text { LMDZ4NE- } \\
\text { MOMED8 } \\
\text { (L'Hévéder } \\
\text { et al. 2013) }\end{array}$ & IPSL & $\begin{array}{l}\text { MPI-ESM- } \\
\text { MR } \\
\text { (Giorgetta } \\
\text { et al. } \\
2013 \text { ) }\end{array}$ & LMDZ & NEMOMED8 & $30 \mathrm{~km}$ & $\begin{array}{l}9-12 \mathrm{~km} \\
43 \mathrm{z}-\mathrm{lev}\end{array}$ & 1 day & MEDAR 40 years \\
\hline $\begin{array}{l}\text { CNRM- } \\
\text { RCSM4 }\end{array}$ & $\begin{array}{l}\text { CNRM- } \\
\text { RCSM4 } \\
\text { (Sevault et al. } \\
\text { 2014) }\end{array}$ & CNRM & \multirow[t]{2}{*}{$\begin{array}{l}\text { CNRM- } \\
\text { CM5 } \\
\text { (Voldoire } \\
\text { et al. } \\
\text { 2011) }\end{array}$} & $\begin{array}{l}\text { ALA- } \\
\text { DIN52 }\end{array}$ & NEMOMED8 & $50 \mathrm{~km}$ & $\begin{array}{l}9-12 \mathrm{~km} \\
43 \mathrm{z}-\mathrm{lev}\end{array}$ & 1 day & MEDAR 140 years \\
\hline $\begin{array}{l}\text { LMD- } \\
\text { CNRM }\end{array}$ & $\begin{array}{l}\text { LMDZ4NE- } \\
\text { MOMED8 } \\
\text { (L'Hévéder } \\
\text { et al. 2013) }\end{array}$ & IPSL & & LMDZ & NEMOMED8 & $30 \mathrm{~km}$ & $\begin{array}{l}9-12 \mathrm{~km} \\
43 \mathrm{z}-\mathrm{lev}\end{array}$ & 1 day & MEDAR 40 years \\
\hline LMD-IPSL & LMD-IPSL & IPSL & $\begin{array}{l}\text { IPSL- } \\
\text { CM5A- } \\
\text { MR } \\
\text { (Dufresne } \\
\text { et al. } \\
\text { 2013) }\end{array}$ & LMDZ & NEMOMED8 & $30 \mathrm{~km}$ & $\begin{array}{l}9-12 \mathrm{~km} \\
43 \mathrm{z}-\mathrm{lev}\end{array}$ & 1 day & MEDAR 40 years \\
\hline $\begin{array}{l}\text { COS- } \\
\text { MOMED }\end{array}$ & $\begin{array}{l}\text { COS- } \\
\text { MOMED } \\
\text { (Cavicchia } \\
\text { et al. 2015; } \\
\text { Conte et al. } \\
\text { 2020) }\end{array}$ & CMCC & $\begin{array}{l}\text { CMCC-CM } \\
\text { (Scoc- } \\
\text { cimarro } \\
\text { et al. } \\
\text { 2011) }\end{array}$ & CCLM & NEMO-MFS & $50 \mathrm{~km}$ & $\begin{array}{l}6-7 \mathrm{~km} \\
72 \mathrm{z}-\mathrm{lev}\end{array}$ & $80 \mathrm{~min}$ & MEDAR 25 years \\
\hline
\end{tabular}

All the simulations cover the period 1950-2005 (HIST) and 2006-2100 (RCP8.5). More information about each RCSM and GCM can be retrieved in the bibliography reported in the first column and in Darmaraki et al. (2019). The MEDAR dataset is extensively described in Rixen et al. (2005). PHC is discussed in Steele et al. (2001)

$I / B C$ Initial/Boundary conditions

and EBUPOM2c RCSMs driven by MPI-ESM-LR (hereafter ROM and EBU-POM) and COSMOMED driven by CMCC-CM (hereafter COSMOMED). For more details on each simulation the reader is referred to the bibliography and the information reported in Table 1 . Note that an error has been recently reported concerning the CNRM-CM5 GCM files for the historical period for CNRM-RCSM4 and LMD-CNRM (http://www.umr-cnrm.fr/cmip5/spip.php? article24). The atmosphere data at the 6-hourly frequency on the model level (6hLev) for the variables ps, ta, ua, va, hus, that were used as atmospheric lateral boundary conditions, do not come from the member r1i1p1 as expected. This simulation has been included in the ensemble given that this error likely has no significant effect on the longterm climate change signal nor on the cyclone analysis performed here (Hochman et al. 2018a; Darmaraki et al.
2019). For additional information on the ocean scheme of the Med-CORDEX RCSMs the reader is referred to Darmaraki et al. (2019) and Soto-Navarro et al. (2020).

Hereafter each simulation analyzed, except if not differently reported, will be identified with the short name of the corresponding RCSM (Table 1, first column).

\subsection{Cyclone detection and tracking algorithm}

Over the last two decades several approaches based on single or multiple automatic tracking algorithms have been applied to characterize cyclones activity in the Mediterranean region (e.g. Trigo et al. 1999; Lionello et al. 2002; Trigo 2006; Nissen et al. 2010; Kouroutzoglou et al. 2010, 2011; Reale and Lionello 2013; Lionello et al. 2016; Flaounas et al. 2018). 
The adoption of different schemes for detecting and tracking cyclones reflects the existence of a wide variety of definitions for a cyclone, which are based on different physical variables such as mean sea level pressure or relative vorticity (e.g. Neu et al. 2013; Hoskins and Hodges 2019a, b).

In this work, we identify cyclones using an automatic scheme specifically developed for the Mediterranean region (Lionello et al. 2002), and later adapted to hemispheric scales (Reale and Lionello 2013; Neu et al. 2013). This algorithm has been extensively applied in previous studies (Lionello et al. 2002; Lionello and Giorgi 2007; Reale and Lionello 2013; Neu et al. 2013; Ulbrich et al. 2013; Lionello et al. 2016; Pinto et al. 2016; Flaounas et al. 2018; Lionello et al. 2019; Reale et al. 2019; Reboita et al. 2020; Lionello et al. 2020; Reboita et al. 2021) and it is based on the search of pressure minima in a sequence of MSLP gridded fields. The procedure involves the partition of the MSLP field at time $t_{0}$ in a certain number of systems by identifying sets of steepest paths leading to the same MSLP minimum. Each point in the MSLP field is connected to the lowest of the 8 nearest-neighbor points, repeating the procedure until a minimum is reached. All the points crossed by a path leading to the same minimum are assigned to the same cyclone. Inflation of the number of detected cyclones is avoided by merging shallow minima to the large adjacent system. The actual position of the cyclone center is a weighted average of the points around the pressure minimum. The trajectory of each system is built by joining the location of the same cyclone center in successive maps. More specifically a box is associated with each center. This box in the meridional direction is centered at cyclone center with a width given by $1.4 \times R$ where $R$ is the average radius of the system, while in the zonal direction the width is asymmetric, with its western side at a distance of $0.3 \times R$, and its eastern side at a distance given by $0.8 \times R$. A cyclone in the map at the time $t_{0}+1$ is assumed to be the continuation of the cyclone in the map if its center is inside such a box. When no center is identified inside the box, the track is terminated. For a detailed description of the tracking algorithm the reader is referred to Lionello et al. (2002) and Reale and Lionello (2013). The final outcome of this automatic algorithm is a list of cyclone tracks, their position as a function of time and the temporal evolution of variables such as: MSLP minimum, Laplacian gradient, depth and radius. In particular the radius of a generic storm $(R)$ is defined as:

$\sqrt{\frac{\sum_{i}^{N} x_{i}^{2}}{N}}$

where $x^{2}{ }_{i}$ represents the distance of a generic point from the center of the cyclone, with $\mathrm{N}$ representing the total number of points associated to a cyclone.
Recent studies based on IMILAST dataset (e.g. Neu et al. 2013; Ulbrich et al. 2013; Pinto et al. 2016; Lionello et al. 2016; Reale et al. 2019) have shown that the choice of a specific tracking scheme could influence the representation of the characteristics of the systems in that region, suggesting that the use of different tracking algorithms on the same original dataset could be a better approach for describing the life cycle of extratropical cyclones. In this study however, we focus on the ability of the ensemble members to reproduce the main characteristics of cyclones in the Mediterranean, rather than on the sensitivity of track climatology to the different cyclone definitions. The sensitivity of our climatology and climate change signal observed with respect to the definition of cyclone is out of the scope of the present manuscript and will be eventually discussed in a future study.

The different RCSMs simulations were completed over a different spatial domain and with different resolution, ranging from 25 to $50 \mathrm{~km}$ in their atmospheric component (Fig. 1 and Table 1). In order to provide a fair comparison between ERA5 and each RCSM (e.g. Kouroutzoglou et al. 2010, 2011; Flaounas et al. 2018) all the 6-hourly model outputs were interpolated onto the ERA5 grid $\left(0.25^{\circ}\right.$, approximately $30 \mathrm{~km}$ ) and on the region shown in blue line in Fig. 1. Moreover, we identified four sub-areas encompassing the main sources of the cyclones crossing the region: North Atlantic (ATL), Northern Africa (AFR), Mediterranean region (MED) and Eastern Europe/Middle East (EEME; Lionello et al. 2016).

The use of ERA5 represents an advantage with respect to the use of former global reanalysis due to its finer resolution, more suitable to describe small scale systems such as the Mediterranean cyclones (Lionello et al. 2016). On the other hand, the use of high-resolution data as input in the tracking algorithm can lead to an inflation in the number of spurious and weak systems which, however, are unlikely to have a strong impact on the climate dynamics and extremes of the Mediterranean region (Neu et al. 2013; Flaounas et al. 2018). In order to filter out all these systems, we consider here cyclones that remain for $>=24 \mathrm{~h}$ in the region and whose maximum intensity (measured by the MSLP) is reached within the Mediterranean area (MED, Fig. 1). Second, we retain only cyclones with a lifetime longer than $24 \mathrm{~h}$ originating above $20^{\circ} \mathrm{N}$ (Neu et al. 2013), with a maximum adjusted deepening rate (Trigo 2006) lower than zero (Reale et al. 2019) and the difference between the minimum and maximum of MSLP along their life cycle larger than $12 \mathrm{hPa}$ (Lionello et al. 2016).

Finally, the period October-March (hereafter ONDJFM) has been chosen to analyze cyclone-related precipitation and wind patterns as it is the period of the year where the influence of cyclone activity on these weather variables has been extensively studied and characterized (see Toreti et al. 
2010; Donat et al. 2011; Lionello et al. 2006; Ulbrich et al. 2012; Reale and Lionello 2013; Nissen et al. 2014; Zappa et al. 2015). Although different techniques exist to associate precipitation and wind patterns to a cyclone (Reale and Lionello 2013; Nissen et al. 2014; Scoccimarro et al. 2014; Villarini et al. 2014; Zappa et al. 2015; Zhang et al. 2020) here we adopted a procedure similar to that of Zappa et al. (2015), i.e.: precipitation and wind speed values in each grid point are attributed to a cyclone if it occurs within a predefined radius from its center. Based on the size distribution of storms analyzed in Sect. 3.1 and following previous analysis (Zappa et al. 2015), the radius has been chosen equal to ten horizontal degrees. Precipitation and wind speed observed beyond this distance are considered as "background" precipitation and wind and not associated with the cyclone activity itself (Zappa et al. 2015). In the case of precipitation, to better focus on possible changes in the intensity of a rainy event on a short time scale all the values are shown in $\mathrm{mm} / \mathrm{h}$.

The climate change signal is evaluated considering the difference between a 25 years period at the end of the twenty-first century in the scenario simulation (2075-2099) and a 25 years period at the end of the historical simulation (1981-2005). Both periods partially encompass the IPCCAR5 end of the 21 st century and baseline time slices respectively (IPCC 2014) and other time slices adopted in previous studies (e.g. Zappa et al. 2015). The statistical significance of the observed differences between the two periods were assessed by means of a Mann-Whitney test at the 95\% significance level.

\section{Results}

\subsection{Evaluation of present cyclone activity in the Mediterranean region}

Figure 2a-i shows the annual density of tracks of cyclones moving through the Mediterranean region in each $1.5^{\circ}$ cell during the period 1981-2005 for ERA5 (a), the multi-model mean of all RCSMs (b) and each RCSM separately (c-i). Following Lionello et al. (2016) the Mediterranean region has been divided in cells of $1.5^{\circ} \times 1.5^{\circ}$. Then, the number of cyclones crossing each cell is counted only once, even if it stays or crosses the cell for more than one time step. The $1.5^{\circ}$ criterion has been chosen to better visualize the spatial distribution of cyclone tracks in the region and to reduce the noise due to the high resolution of original data. Moreover, in order to assess the level of agreement among RCSMs, we use the normalized standard deviation, which is the ratio between the standard deviation of the multi-model mean and the multi-model mean ( std $_{\text {multi-model-mean }} /$ multi-model mean; Lionello et al. 2016; Reale et al. 2019) and is shown in the panel (j). A small value of normalized standard deviation corresponds to a high level of agreement among the RCSMs (Lionello et al. 2016).

The relatively low number of tracks observed in ERA5 (a) with respect to what found in previous multi-tracking/multi-model studies using ERA-Interim as reference (e.g. Lionello et al. 2016; Flaounas et al. 2018) is a direct consequence of the strict criteria adopted for identifying cyclones crossing the region (see Sect. 2.2). The spatial patterns of cyclones tracks are qualitatively reproduced in the Mediterranean region by the multi-model mean (b) and each RCSM (c-i) compared to ERA5 (a). Relative maxima are captured in the Gulf of Genoa, Western Mediterranean, North Africa and in proximity to Cyprus in agreement with previous studies (e.g. Alpert et al. 1990; Trigo et al. 1999; Lionello et al. 2006, 2016; Campins et al. 2010; Ulbrich et al. 2012; Flaounas et al. 2018). The spatial correlation coefficient between each RCSM and ERA5 is high, ranging from 0.73 (CNRM-RCSM4) to 0.89 (LMD-CNRM). The level of agreement among RCSMs is relatively high in the Western and Central Mediterranean region, while it is lower around Cyprus and in general at the boundaries of the Mediterranean Sea (Fig. 2j).

Figure 3 shows the relative differences between the multi-model mean (a) and each RCSM (b-h) with ERA5 (Fig. 2a). Most of the RCSMs and the multi-model ensemble underestimate more than $50 \%$ the maxima observed in ERA5 over the Gulf of Genoa and the Iberian Peninsula. Of the same magnitude is the overestimation of the signal over Northern Africa and in the Cyprus area. LMD-CNRM (Fig. 3e) and LMD-MPI (Fig. 3f) show higher values of the density of tracks in the western and central part of the basin. On the other hand, LMD-IPSL (Fig. 3h) has an opposite behavior with lower values over most of the two regions. Besides, EBU-POM in Fig. 3c (ROM in Fig. 3b) underestimates (overestimates) the maximum observed in the area around Cyprus. Most of the differences observed are not statistically significant except for a limited number of areas and RCSMs such as in the Gulf of Genoa in the case of EBU-POM (Fig. 3c), CNRM-RCSM4 (Fig. 3d), LMD-IPSL (Fig. 3g) and COSMOMED (Fig. 3h),over the Ionian Sea in the case of EBU-POM (Fig. 3c) and LMDIPSL (Fig. 3g), and around Cyprus in the case of the multimodel mean (Fig. 3a) and ROM (Fig. 3b).

In all the RCSMs, the majority of cyclones crossing the region (more than 50\%) are formed within the Mediterranean basin (Fig. 4a). RCSMs also agree that most of the remaining systems crossing the region originate either over the Atlantic or over Northern Africa, while the contribution from the Middle East and Eastern Europe areas is quite small. However, RCSMs tend to overestimate the percentage of cyclones originating in North Africa (up to $15 \%$ in CNRM-RCSM4 with respect to ERA5). At the same time ROM, EBU-POM, LMD-MPI, LMD-CNRM 
(a) ERA5 DENSITY TRACKS 1981-2005

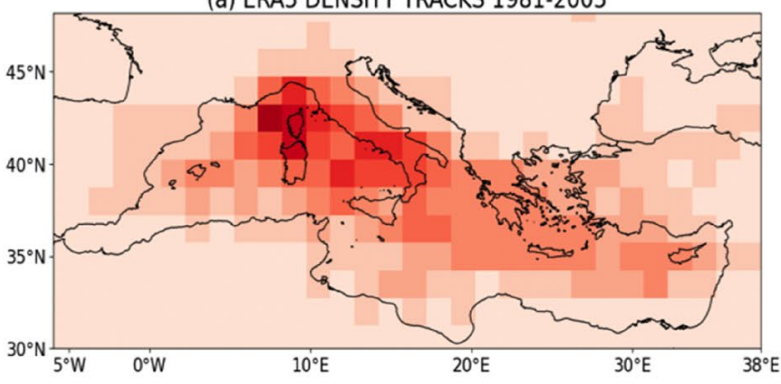

(c) ROM 1981-2005

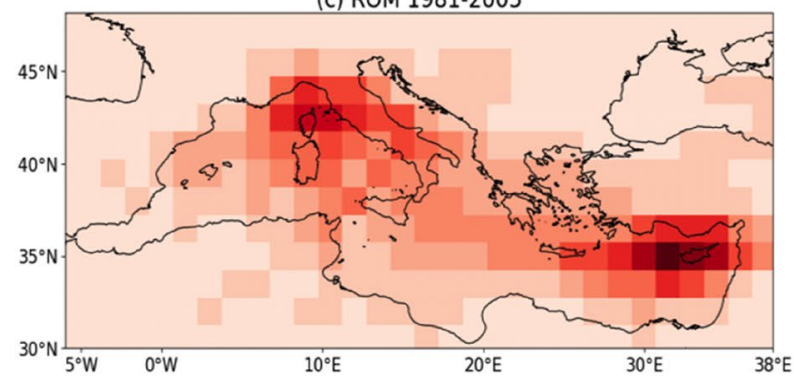

(e) CNRM-RCSM4 1981-2005

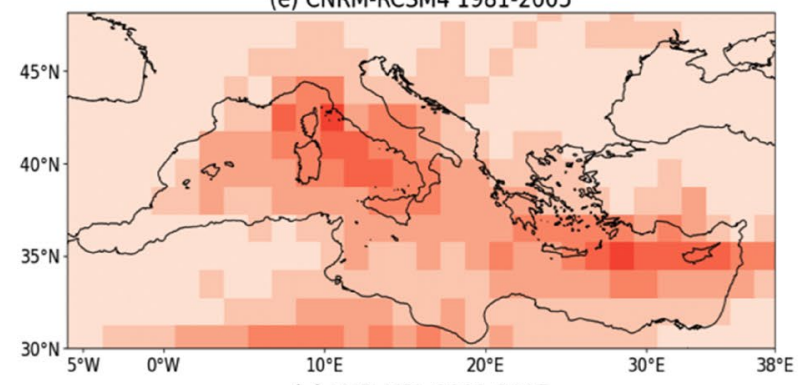

(g) LMD-MPI 1981-2005
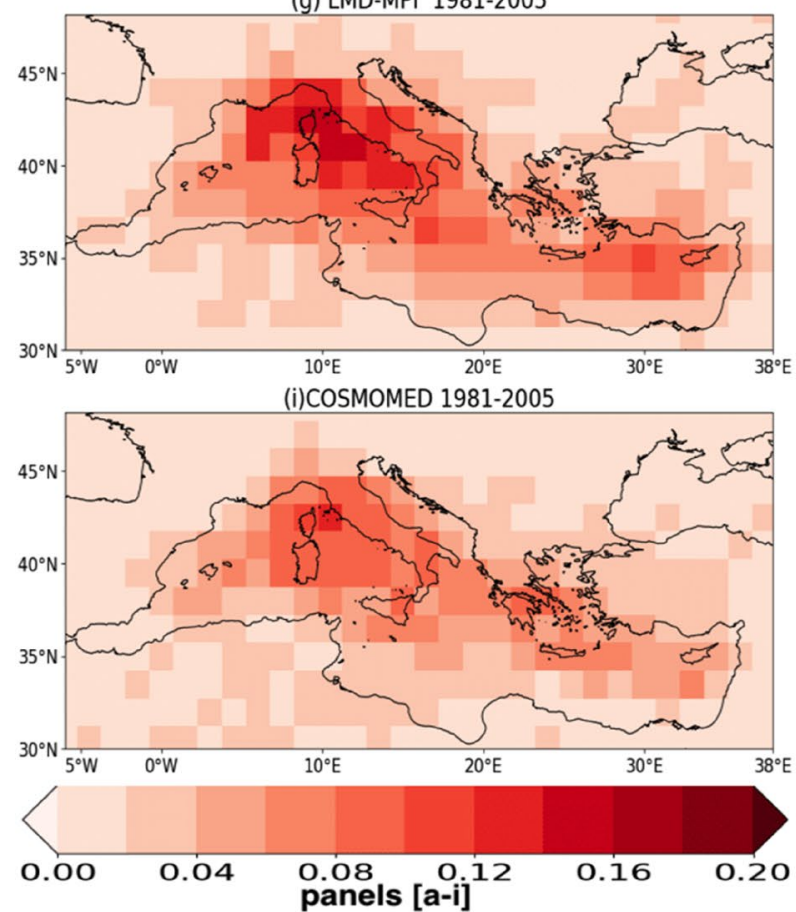

panels $[\mathrm{a}-\mathrm{i}]$

Fig. 2 Spatial distribution of annual mean number of cyclone tracks in each cell of $1.5^{\circ}$ in the period 1981-2005 for ERA5 (a), multimodel mean (ENSEMBLE, b), ROM (c), EBU-POM (d), CNRM- (b) ENSEMBLE 1981-2005

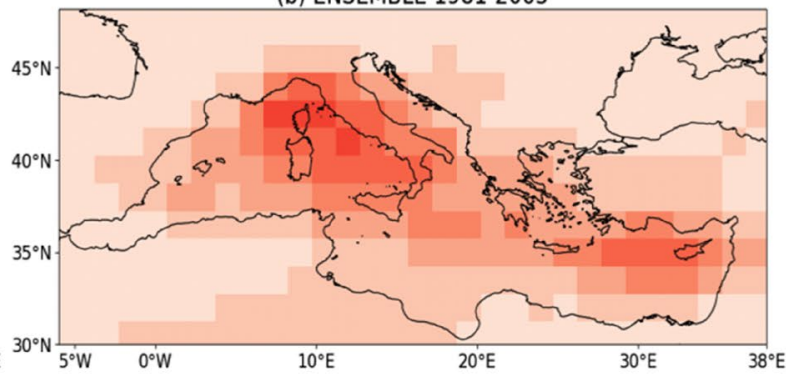

(d) EBU-POM 1981-2005

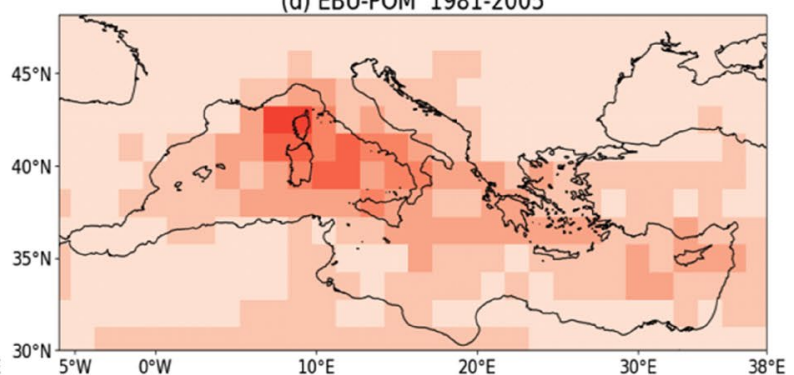

(f) LMD-CNRM 1981-2005

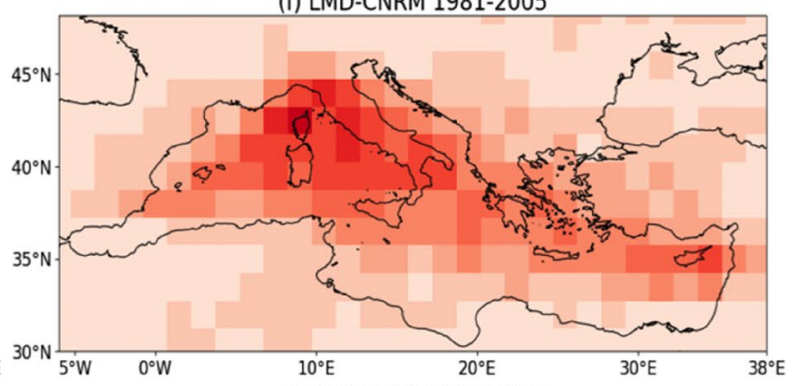

(h) LMD-IPSL 1981-2005
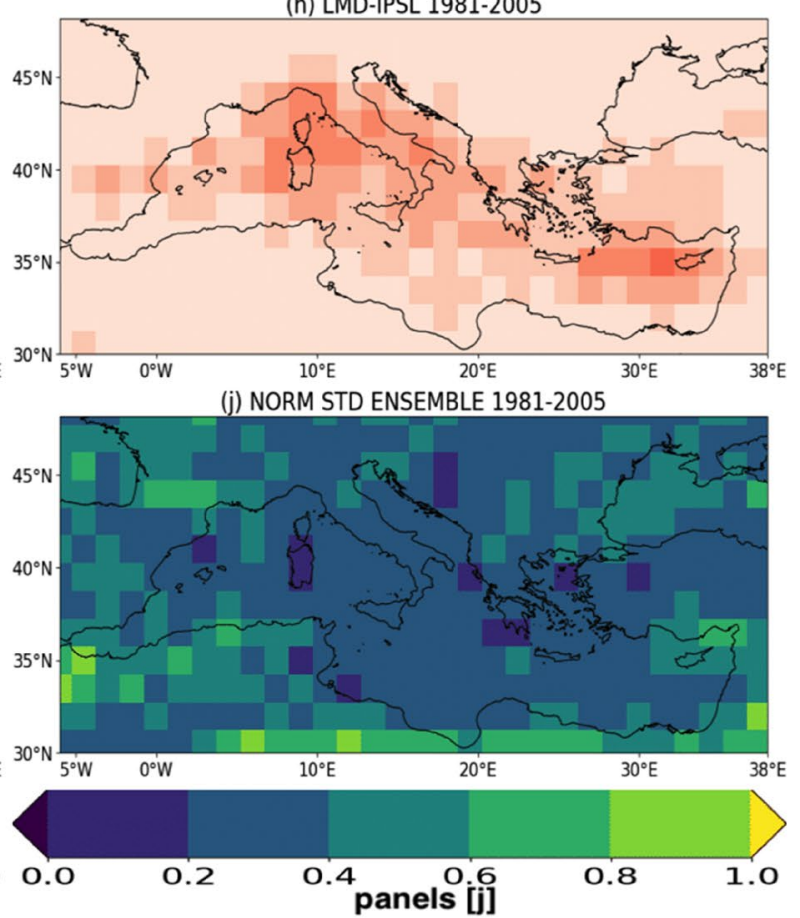

RCSM4 (e), LMD-CNRM (f), LMD-MPI (g), LMD-IPSL (h) and COSMOMED (i). Panel (j) shows the normalized standard deviation among all the RCSMs 

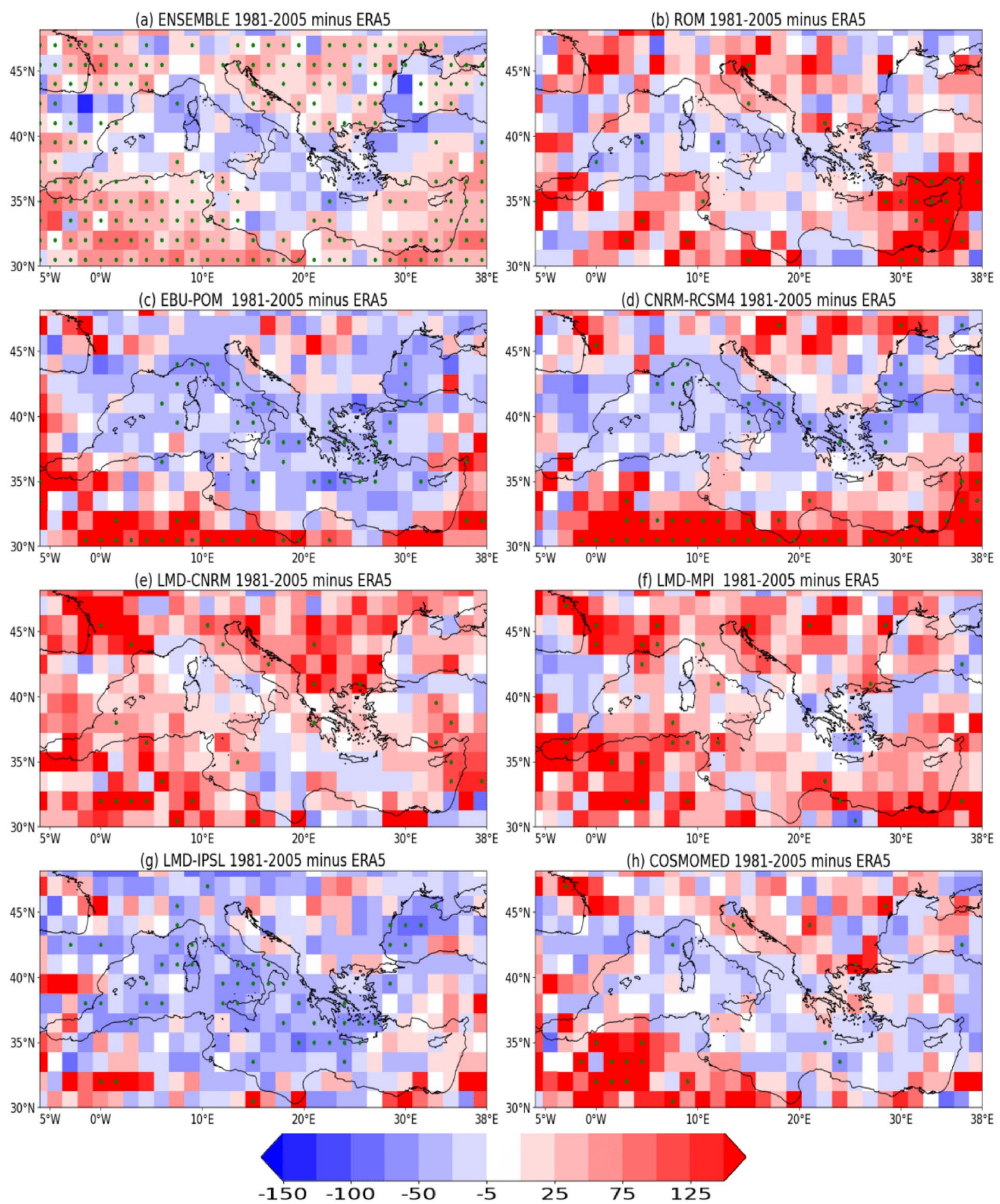

Fig. 3 Spatial distribution of differences with respect to ERA5 (in $\%$ ) in the annual number of cyclone tracks in each cell of $1.5^{\circ}$ in the period 1981-2005 in the multi-model mean (ENSEMBLE, a), ROM (b), EBU-POM (c), CNRM-RCSM4 (d), LMD-CNRM (e), LMD-

MPI (f), LMD-IPSL (g) and COSMOMED (h). Green dots mark the cells where the difference with respect to ERA5 is statistically significant with $p<0.05$ 
(a) Cyclogenesis area

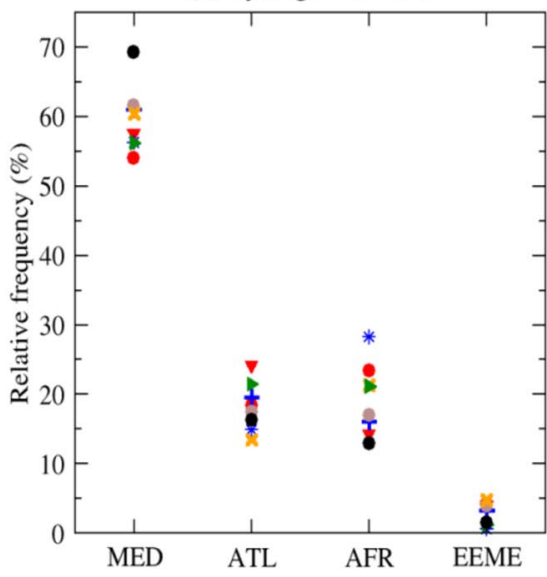

(d) MAX ADR

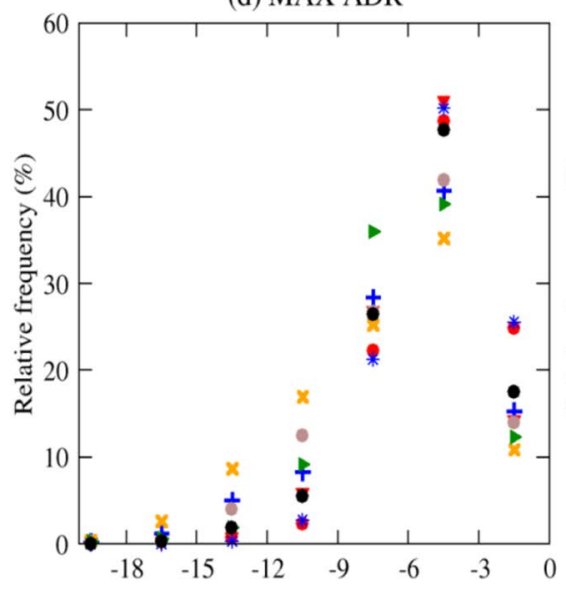

(b) Monthly cycle

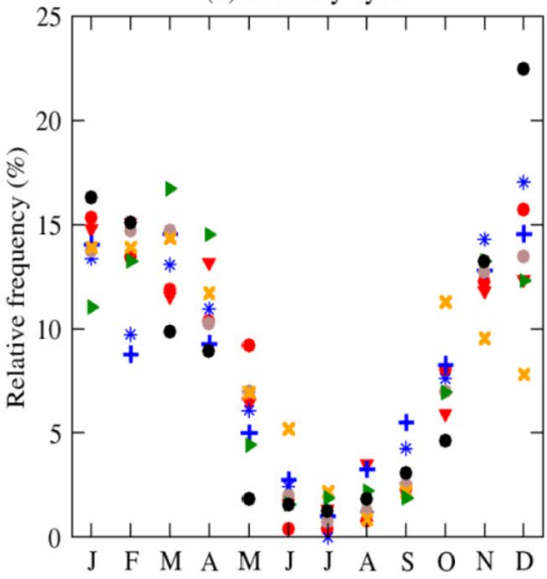

(e) RADIUS

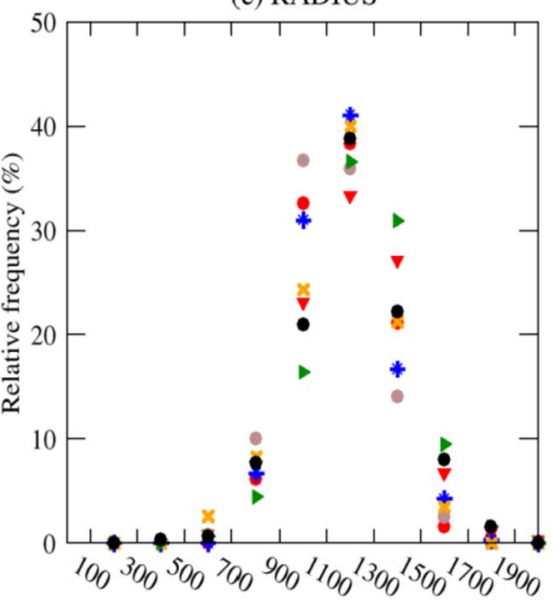

(c) MIN MSLP

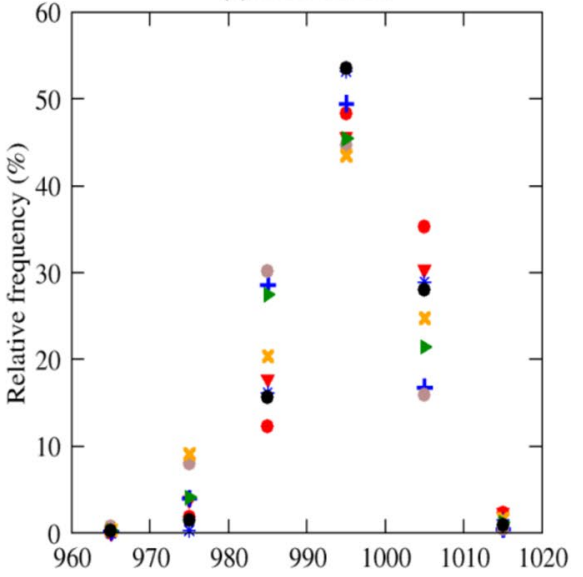

Fig. 4 Relative frequency (in \%) of cyclones in function of: a their area of formation, $\mathbf{b}$ the month when the system is detected, $\mathbf{c}$ their lifetime MSLP minimum considering $10 \mathrm{hPa}$ wide bins and covering the range from 960 to $1010 \mathrm{hPa}, \mathbf{d}$ their lifetime maximum adjusted deepening rate (ADR) considering $3 \mathrm{hPa} / 6 \mathrm{~h}$ wide bins and covering the range from -21 to $0 \mathrm{hPa} / 6 \mathrm{~h}$, e their average radius considering $200 \mathrm{~km}$ wide bins and covering the range from 100 to $1900 \mathrm{~km}$ and COSMOMED overestimate the percentage of cyclones entering into the RCSM domain from the Atlantic (up to $7 \%$ of ROM), while the opposite is found in CNRMRCSM4 and LMD-IPSL. Finally, in the Middle East/Eastern Europe region the underestimation/overestimation in the ensemble of RCSMs is in absolute values lower than $3 \%$.

Despite some relevant overestimation/underestimation observed in each single month (for example - $14 \%$ observed in December in LMD-IPSL), the seasonal cycle of cyclone frequency is captured by all RCSMs (Fig. 4b), with higher frequency in the extended winter season (October-March) and lower frequency in summer (June-August), as already demonstrated by Lionello et al. (2016), Flaounas et al. (2018) and Hochman et al. (2018b).

The RCSMs agree with ERA5 in showing that the most likely minimum value of MSLP (Fig. 4c) and maximum value of the maximum Adjusted Deepening Rate (ADR; Trigo 2006) for a Mediterranean cyclone during its life cycle are in the range of [990; 1000] $\mathrm{hPa}$ and $[-6 ;-3] \mathrm{hPa} / 6 \mathrm{~h}$ respectively (Fig. 4d). In the LMD, COSMOMED and ROM simulations, cyclones tend to be deeper than those in ERA5 by about $10 \mathrm{hPa}$. On the other hand, in the EBU-POM simulation, cyclones are shallower than those in ERA5. Moreover, both LMD and COSMOMED simulations are also characterized by cyclones with higher ADR than ERA5. The differences observed, with the only exception of ROM, are statistically significant.

Finally, concerning the average radius (Fig. 4e) most RCSMs are in agreement with ERA5 in showing that the most likely value for this variable falls in the interval (1100; 1300) km. ROM and COSMOMED tend to simulate wider 
(a) ERA5 HOURLY CYCL PREC 1981-2005

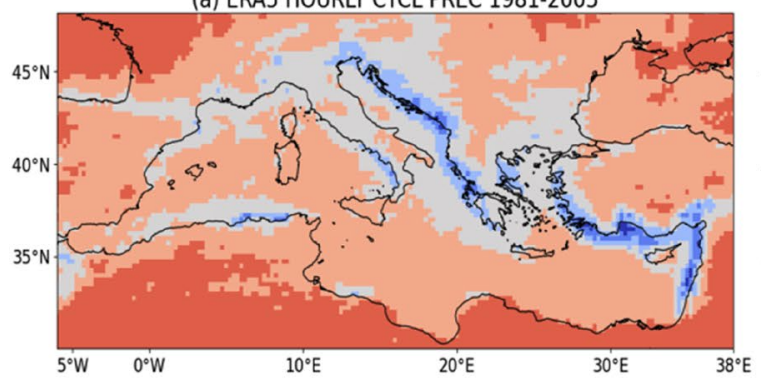

(c) ROM HOURLY CYCL PREC 1981-2005

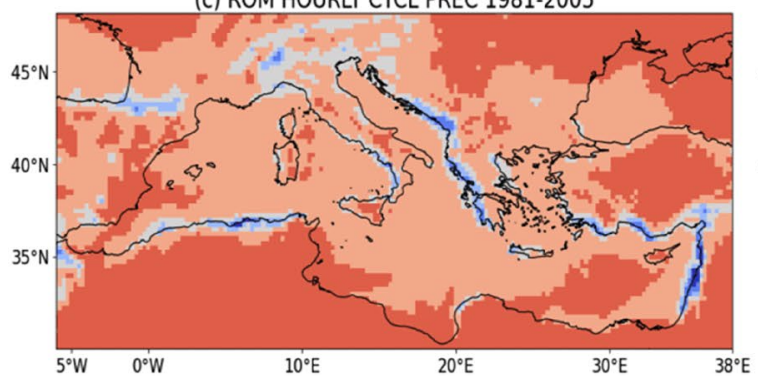

(e) CNRM-RCSM4 HOURLY CYCL PREC 1981-2005

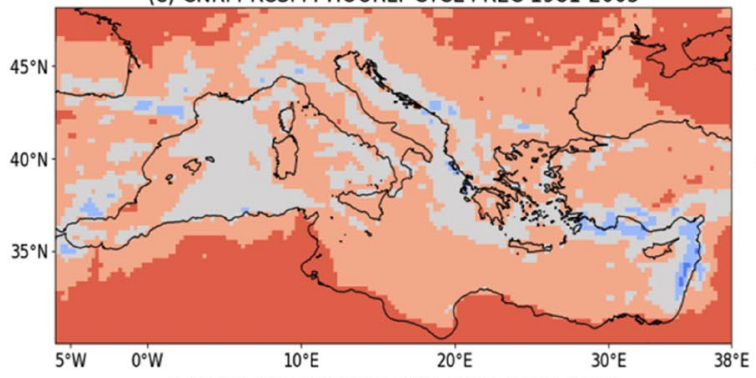

(g) LMD-MPI HOURLY CYCL PREC 1981-2005

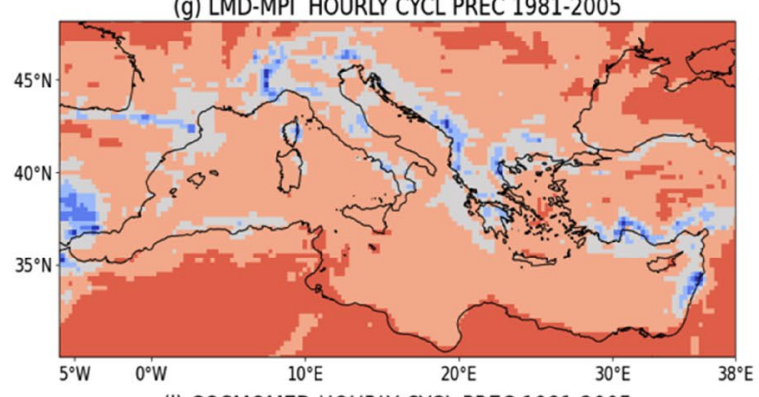

(i) COSMOMED HOURLY CYCL PREC 1981-2005

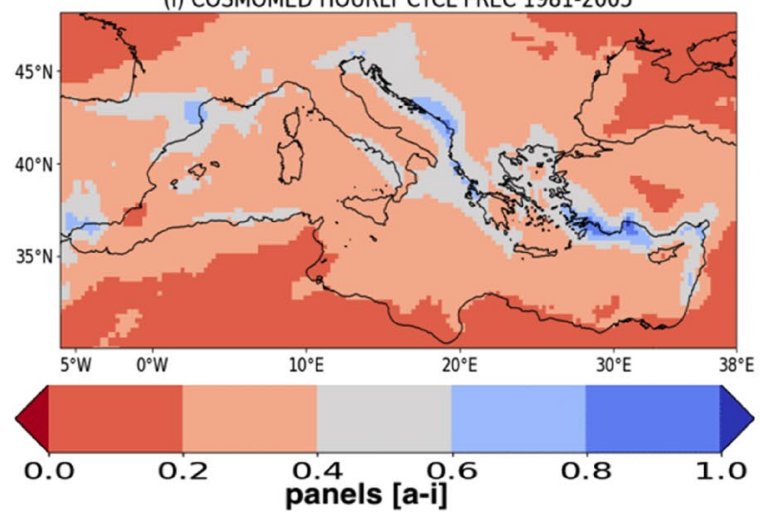

(b) ENSEMBLE HOURLY CYCL PREC 1981-2005

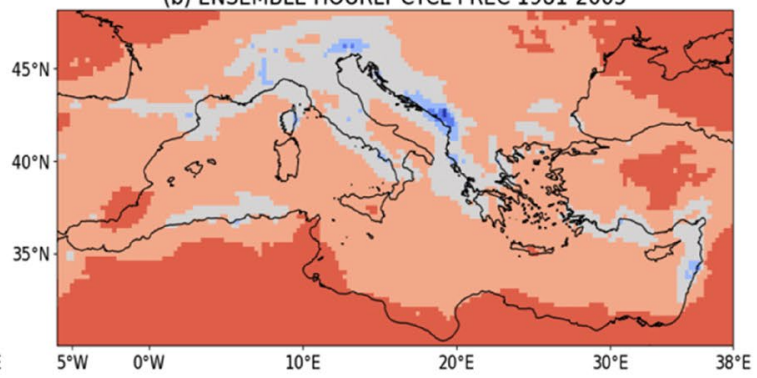

(d) EBU-POM HOURLY CYCL PREC 1981-2005

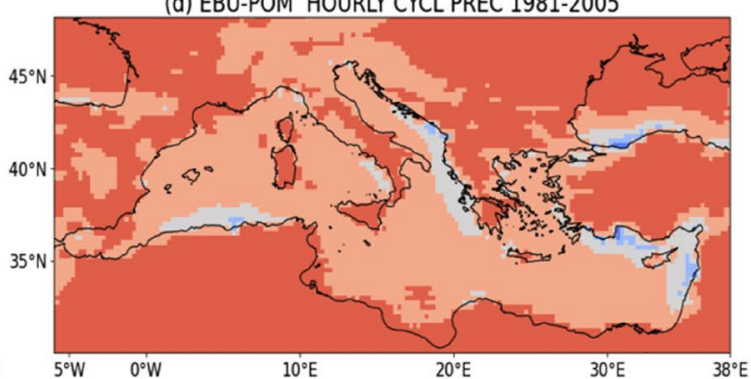

(f) LMD-CNRM HOURLY CYCL PREC 1981-2005

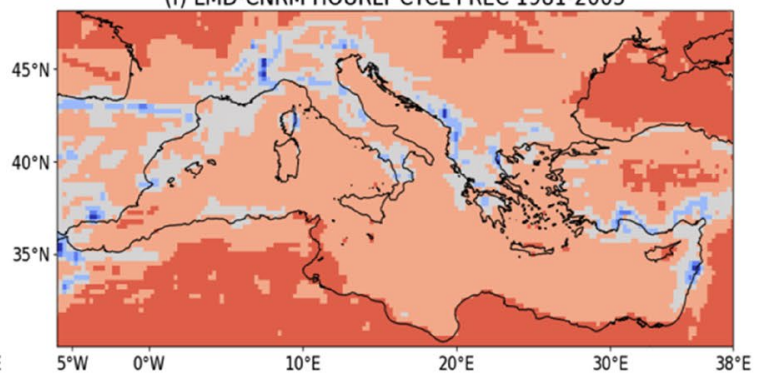

(h) LMD-IPSL HOURLY CYCL PREC 1981-2005

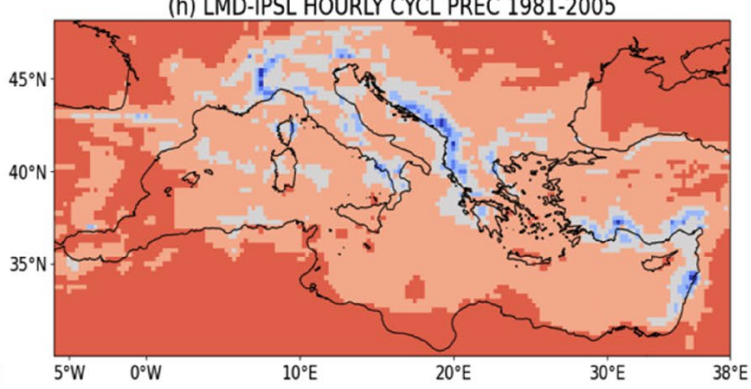

(j) NORM STD ENSEMBLE CYCL PREC 1981-2005
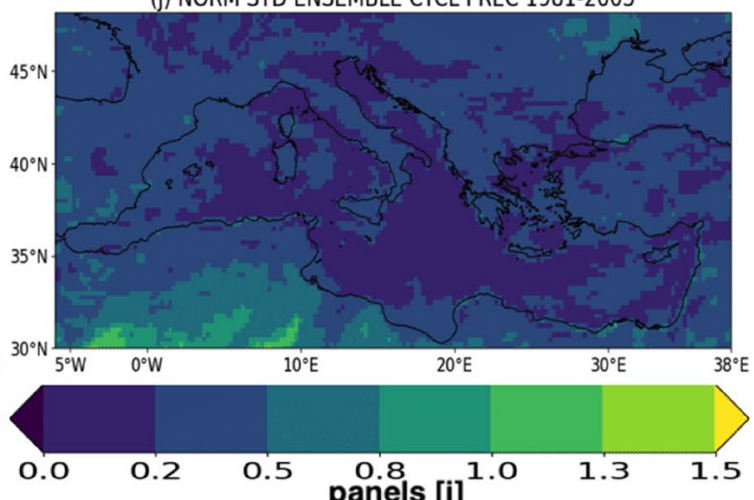

Fig. 5 As Fig. 2 but for the annual hourly precipitation associated with cyclones moving through the Mediterranean region (in $\mathrm{mm} / \mathrm{h}$ ) in the extended winter season (ONDJFM) of 1981-2005 
cyclones compared to ERA5. Indeed, significant overestimations of about $7 \%$ and $9 \%$ of the frequency of cyclones in the range $1300-1500 \mathrm{~km}$ are found, respectively.

(a) ENSEMBLE HOURLY CYCL PREC 1981-2005 minus ERA5

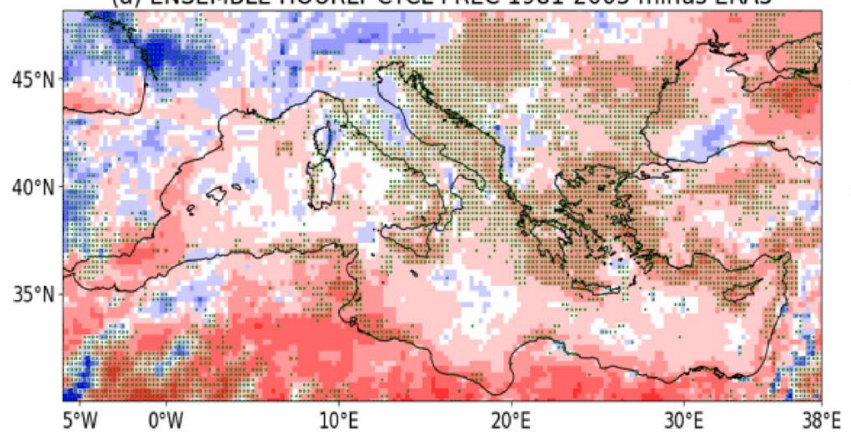

(c) EBU-POM HOURLY CYCL PREC 1981-2005 minus ERA5

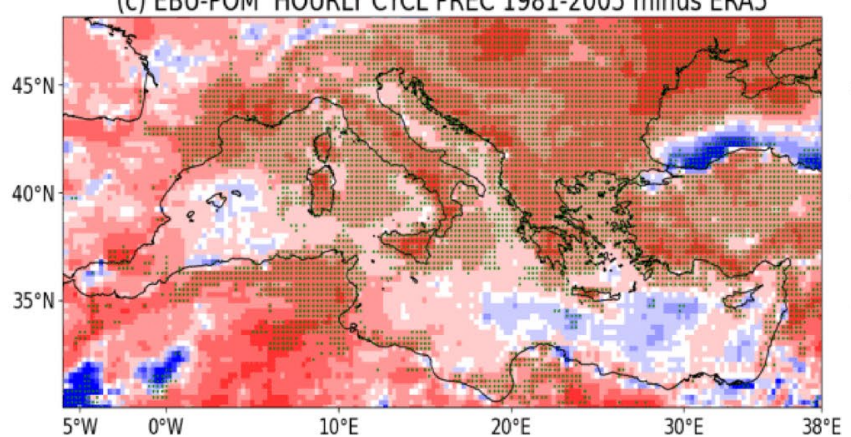

(e) LMD-CNRM HOURLY CYCL PREC 1981-2005 minus ERA5

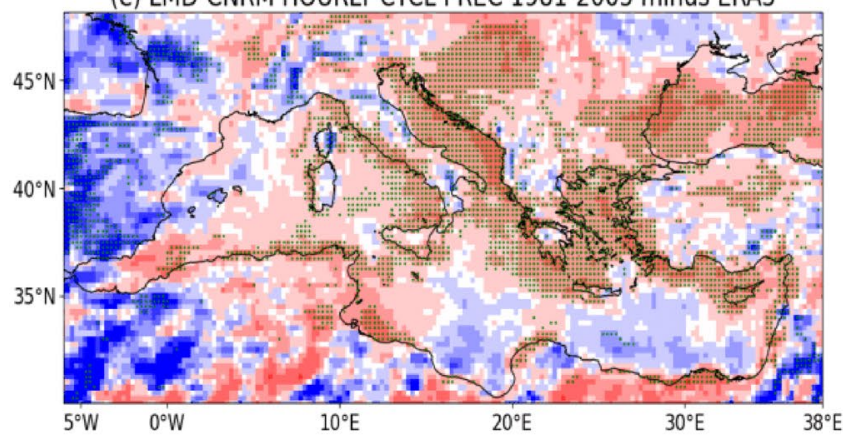

(g) LMD-IPSL HOURLY CYCL PREC 1981-2005 minus ERA5

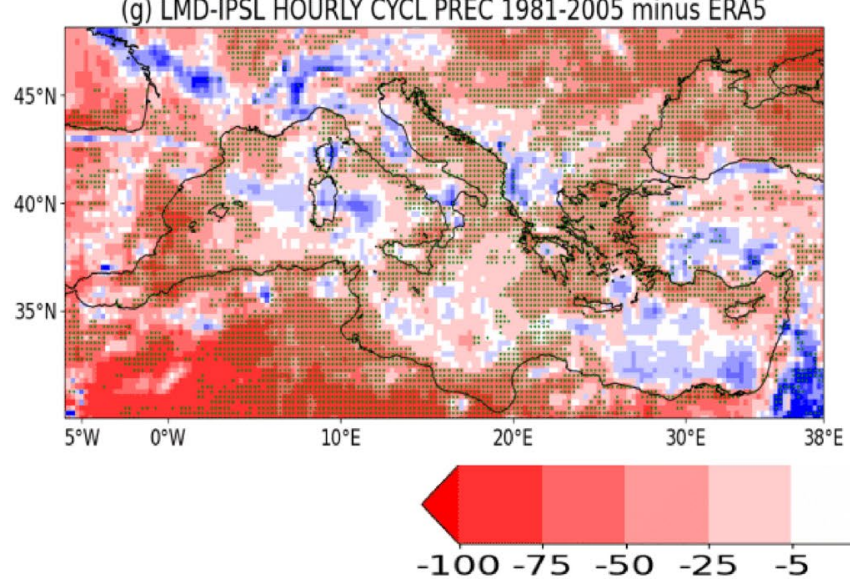

Figure 5 shows the annual average hourly precipitation associated with each cyclone in ERA5 (a), the ensemble average of all RCSMs (b) and each RCSM separately (c-i)

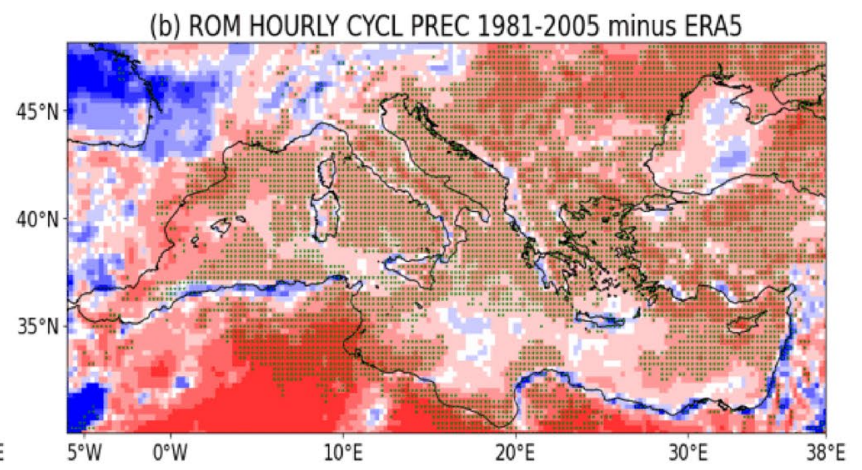

(d) CNRM-RCSM4 HOURLY CYCL PREC 1981-2005 minus ERA5

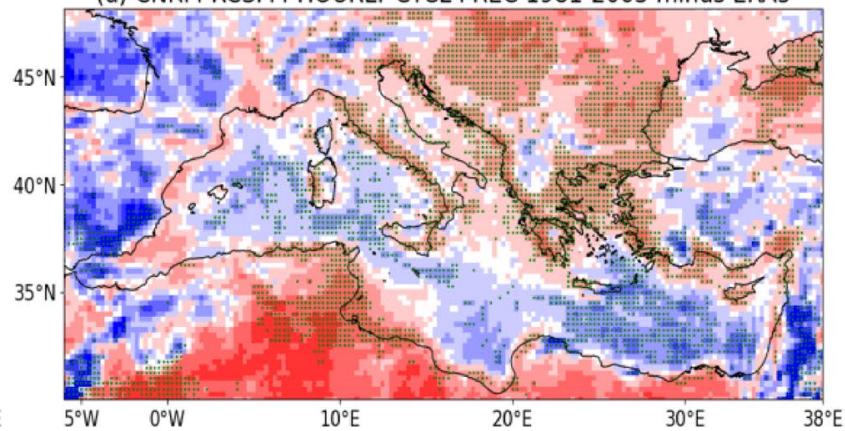

(f) LMD-MPI HOURLY CYCL PREC 1981-2005 minus ERA5

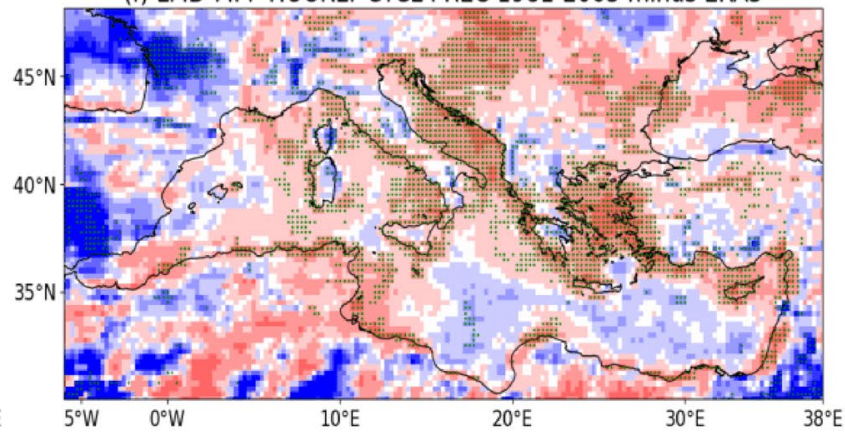

(h) COSMOMED HOURLY CYCL PREC 1981-2005 minus ERA5

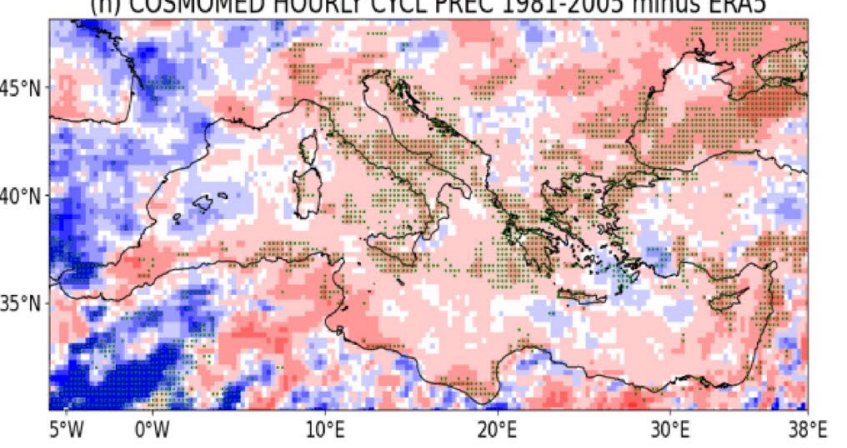

Fig. 6 Same as Fig. 3 but for the annual hourly precipitation associated with cyclones moving through the Mediterranean region (in mm/h) in the extended winter season (ONDJFM) of 1981-2005 
during the extended winter season ONDJFM 1981-2005. Panel (j) shows the level of agreement among RCSMs measured by the normalized standard deviation.

Precipitation patterns associated with cyclones are qualitatively well captured by each RCSM in comparison to ERA5. Some relative maxima are observed along the Algerian, Eastern Adriatic, Ionian, Anatolian and Eastern Mediterranean coastlines (e.g. Zappa et al. 2015). Moreover, other precipitation maxima are observed over the Alps and the Pyrenees. The level of agreement among RCSMs is relatively higher over the Mediterranean Sea while it tends to decrease over land.

However, most of the simulations overestimate (more than $50 \%$ ) precipitation over mountain peaks, in agreement with previous studies (Fig. 6; Fantini et al. 2018; Reale et al. 2020). Another common feature among RCSMs is the underestimation of the precipitation over part of the Adriatic Sea, the Balkan area and Aegean Sea. Moreover, ROM (Fig. 6b) and EBU-POM (Fig. 6c) display underestimations of about $50 \%$ precipitation over Western and Central part of the Mediterranean region. CNRM-RCSM4 (Fig. 6d), LMDCNRM (Fig. 6e), LMD-MPI (Fig. 6f) and COSMOMED (Fig. 6h) simulates values of precipitation almost double with respect to ERA5 (Fig. 5a) over the Iberian Peninsula. Drier conditions are observed in this area in the other ensemble members.

Direction and speed of the winds associated with cyclones are also qualitatively well captured by the multimodel mean (Fig. 7b) and by each RCSM (Fig. 7 c, i) in comparison to ERA5 (Fig. 7a). Multi-model-mean and each RCSM simulation captures the northerly direction of the winds associated with cyclone activity over the Aegean Sea, the westerly winds flowing along the Northern Africa coastlines, the northerly and easterly flows over the gulf of Lions and Northern Adriatic Sea, which correspond to the location of Mistral and Bora wind patterns respectively. Most RCSMs capture the spatial pattern of wind magnitude in the region with some relative maxima observed in the gulf of Lions, Northern African coastlines, Northern Adriatic, Southern Ionian and over the Aegean Sea. As in the case of precipitation, the spread measured by the normalized standard deviation is low over the Mediterranean Sea, while it increases over the land with some maxima. These findings are spatially coherent with the presence of some topographic features such as the Alps and the Pyrenees (Fig. 7j). However, RCSMs tend also to overestimate (the values simulated are almost double with respect to those observed in ERA5) the intensity of wind flowing through the strait of Otranto (Fig. 8). At the same time, they tend to underestimate $(\sim 50 \%)$ the intensity of wind flowing through the Aegean Sea (Fig. 8). Moreover, some differences are also observed among RCSMs concerning the maximum associated with the Mistral wind in the Gulf of Lions. Finally,
CNRM-RCSM4 underestimates the intensity of wind flowing over the Southern Ionian and Levantine basin (Fig. 8d).

In summary, although some noticeable quantitative biases exist in the ensemble of Med-CORDEX RCSMs simulations, the models qualitatively capture key cyclone characteristics, in particular, the spatial patterns and there are no extreme outliers. We therefore conclude that all simulations can be considered as plausible representations of Mediterranean cyclones and we therefore use them all for the analysis of the response of cyclone activity to increased greenhouse gases concentrations in the next section.

\subsection{Cyclone activity in the Mediterranean region at the end of twenty-first century}

Figure 9 shows the difference (in \%) between the period 2075-2099 and 1981-2005 of the annual density of the tracks of cyclones crossing the Mediterranean region in the RCSMs multi-model mean (a) and individual RCSM (b-h).We define a climate change signal as "robust" in our ensemble if it fulfills two criteria: (i) more than 5 out of 7 models agree on the sign of the change and (ii) the normalized standard deviation of changes observed is (in absolute value) lower than 1 (Akperov et al. 2019).

The ensemble average shows a general decrease in the number of cyclones crossing the region of up to $~ 50 \%$ (Fig. 9a). The observed decrease is robust over the Tyrrhenian Sea, Southern Italy, part of the Gulf of Genoa, over part of Northern Africa, the Eastern part of the Ionian Sea, the Anatolian Peninsula and in the area between Crete and Cyprus. Despite this overall decrease, an increase in some areas is also evident. ROM (Fig. 9b), EBU-POM (Fig. 9c), CNRM-RCSM4 (Fig. 9d) and LMD-MPI (Fig. 9f) show an increase in cyclone track density over most of Western Europe and the Iberian Peninsula. At the same time, an increase in density of tracks over the Ionian Sea and most of the Levantine basin is projected by CNRM-RCSM4 (Fig. 9d) and only over part of the Ionian Sea in LMD-CNRM (Fig. 9e). EBU-POM shows a positive signal located over the Middle-East (Fig. 9c). In general, the observed statistically significant differences between the two periods in each RCSM are mostly negative and located over the Mediterranean Sea (Fig. 9b-h). Among the RCSMs the only statistically significant signal encompassing most of the Mediterranean storm track is observed in LMD-IPSL (Fig. 9g). The level of agreement among RCSMs (not shown) is low over France, Northern Africa, Gulf of Lions, over the Ionian Sea and in the Levantine basin, around the Cyprus area and over the Middle-East.

Figure 10a and Fig. 10b show the changes in the area of the origin and the seasonality of cyclones crossing the region, respectively. Most RCSMs project a decrease of the number of cyclogenesis processes in the Mediterranean 

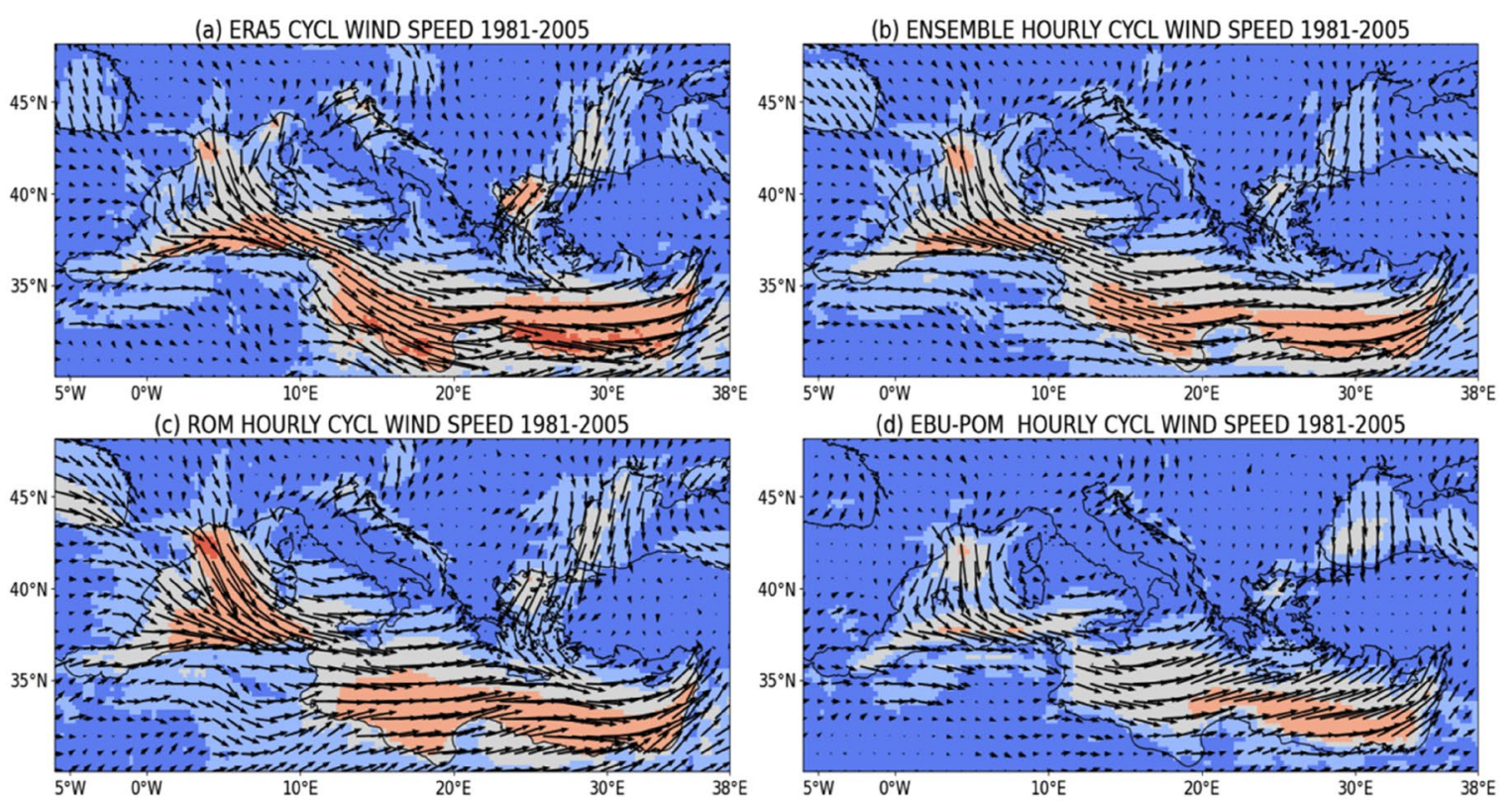

(e) CNRM-RCSM4 HOURLY CYCL WIND SPEED 1981-2005
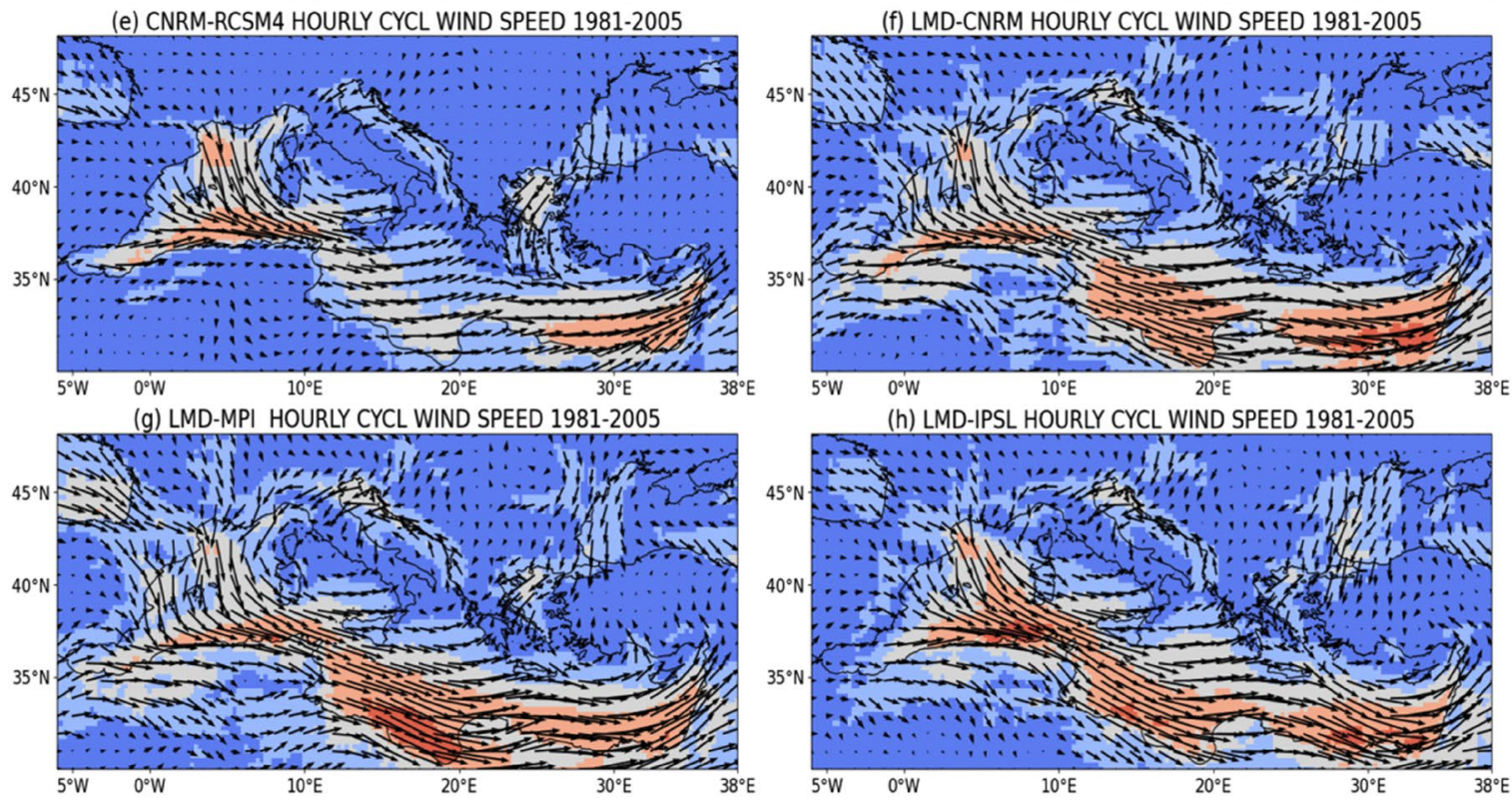

(i) COSMOMED HOURLY CYCL WIND SPEED 1981-2005
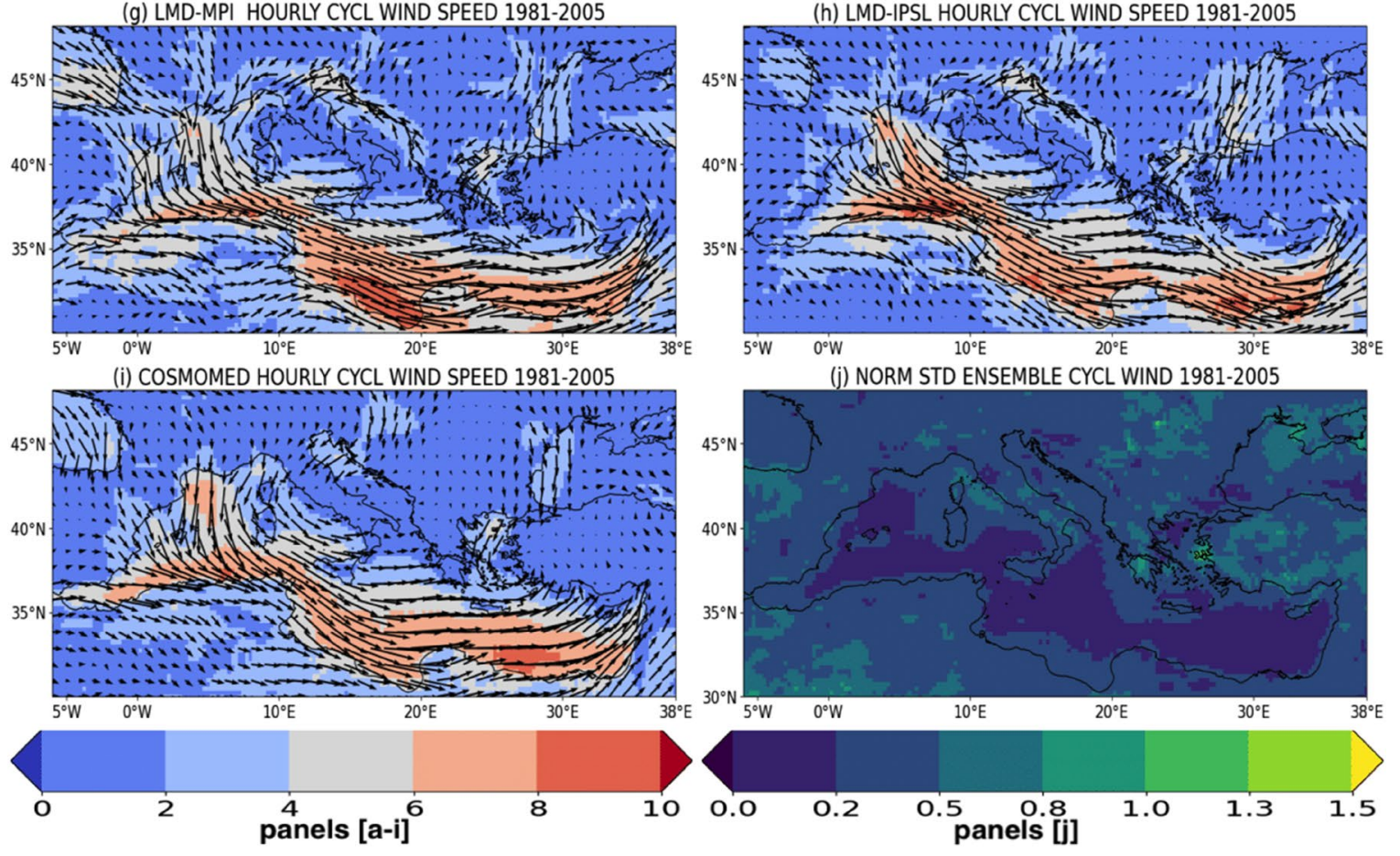

Fig. 7 Same as Fig. 5 but for the wind speed (in $\mathrm{m} / \mathrm{s}$ ) 
(a) ENSEMBLE CYCL WIND SPEED 1981-2005 minus ERA5

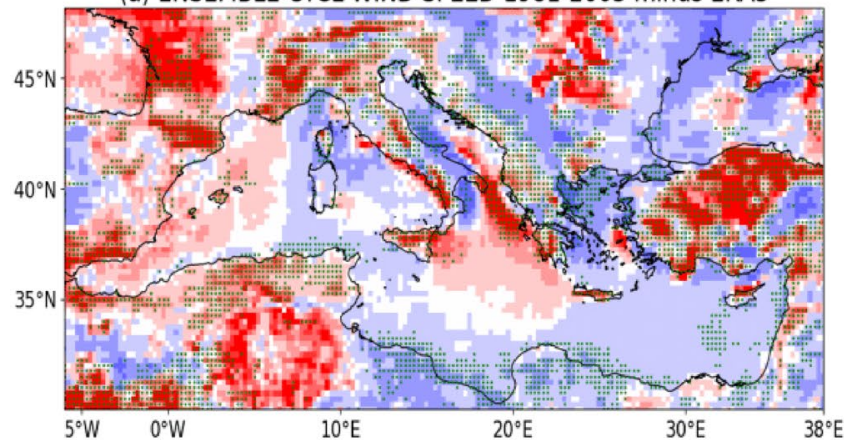

(c) EBU-POM HOURLY CYCL WIND SPEED 1981-2005 MINUS ERA5

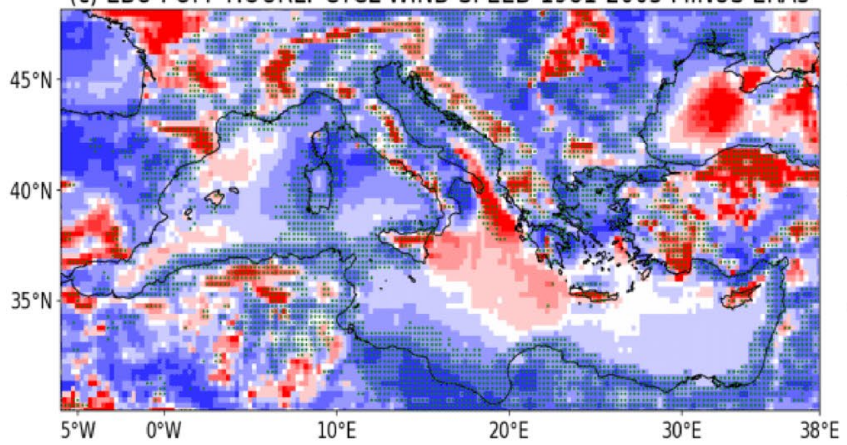

(e) LMD-CNRM HOURLY CYCL WIND SPEED 1981-2005 MINUS ERA5

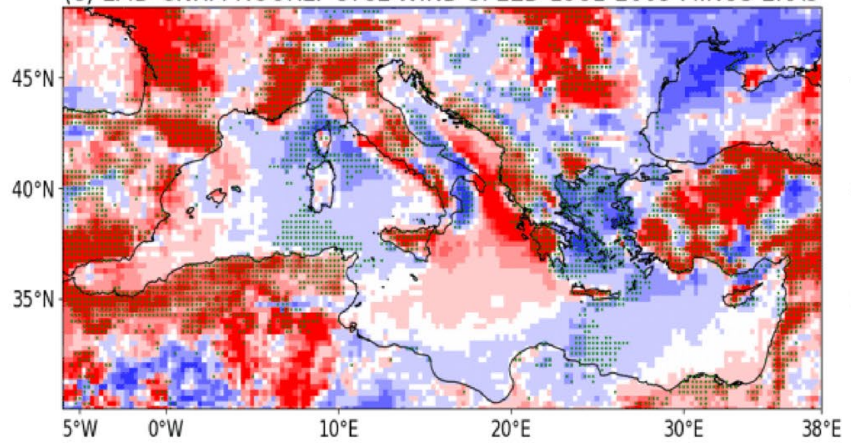

(g) LMD-IPSL HOURLY CYCL WIND SPEED 1981-2005 MINUS ERA5

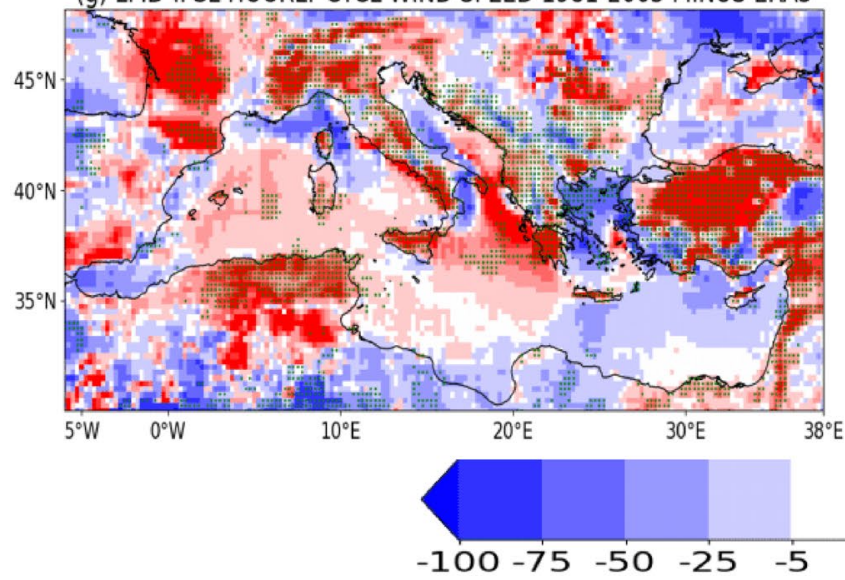

(b) ROM HOURLY CYCL WIND SPEED 1981-2005 MINUS ERA5

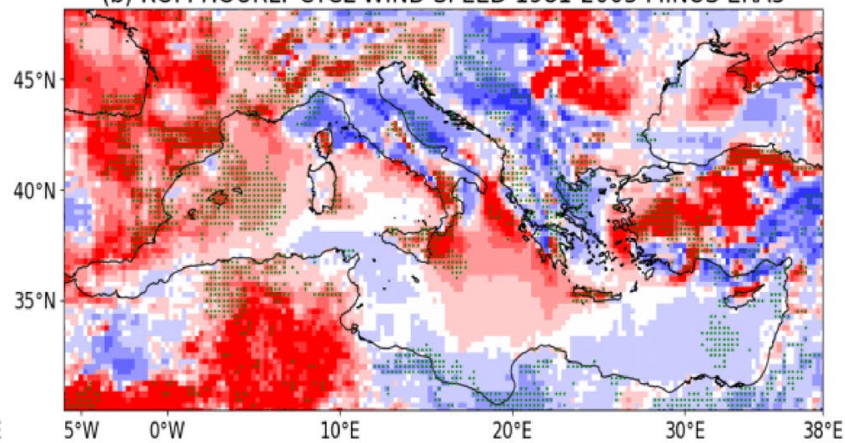

(d) CNRM-RCSM4 HOURLY CYCL WIND SPEED 1981-2005 MINUS ERA5

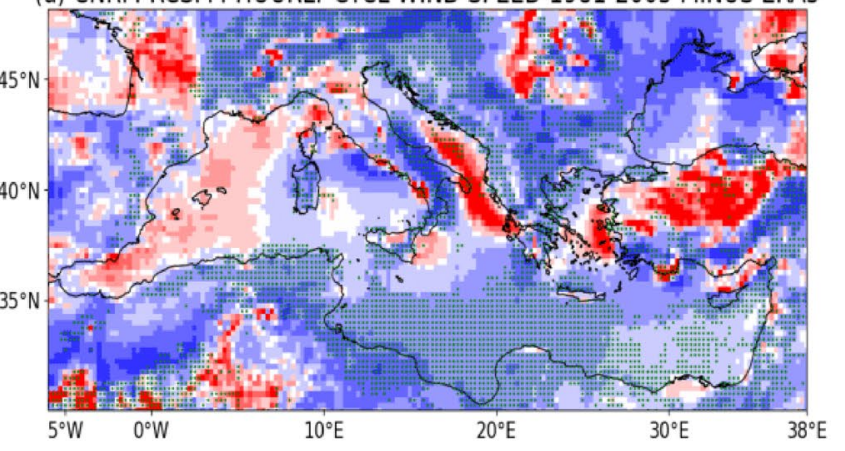

(f) LMD-MPI HOURLY CYCL WIND SPEED 1981-2005 MINUS ERA5

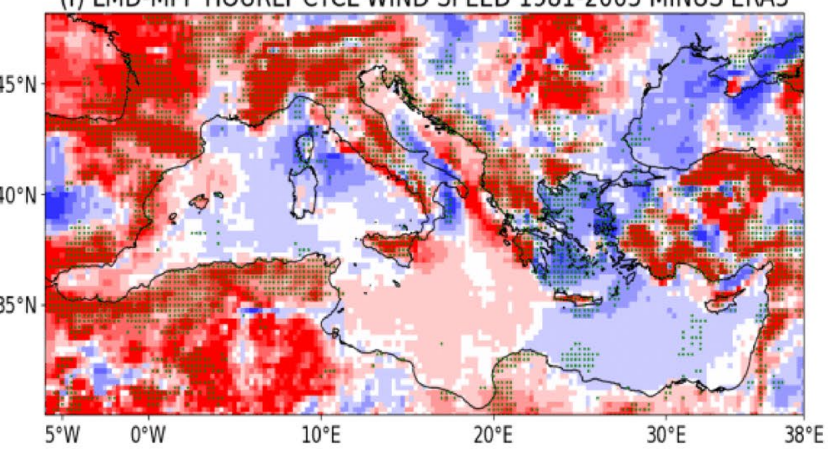

(h) COSMOMED HOURLY CYCL WIND SPEED 1981-2005 MINUS ERA5

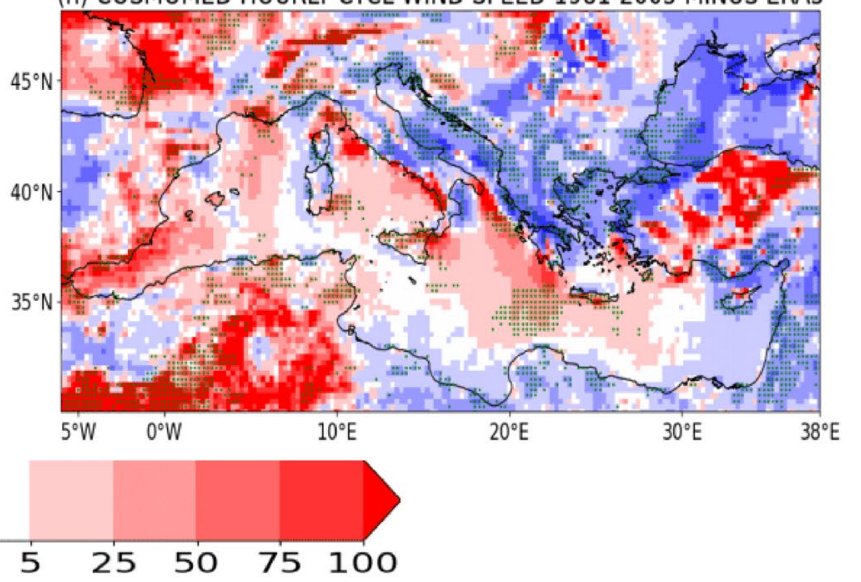

Fig. 8 Same as Fig. 6 but for the wind speed (in $\mathrm{m} / \mathrm{s}$ ) 
(a) ENSEMBLE 2075-2099 minus ENSEMBLE 1981-2005

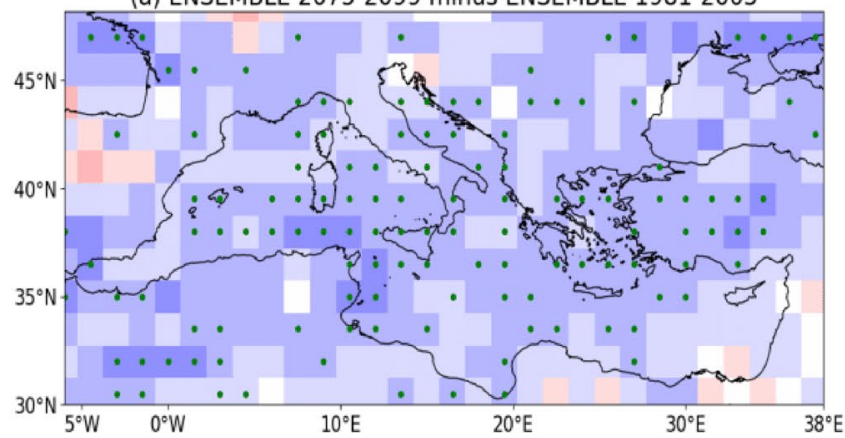

(c) EBU-POM 2075-2099 minus 1981-2005

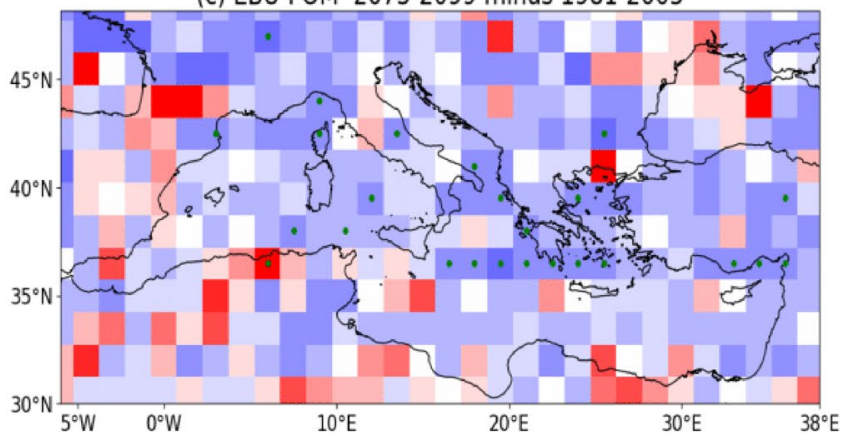

(e) LMD-CNRM 2075-2099 minus 1981-2005

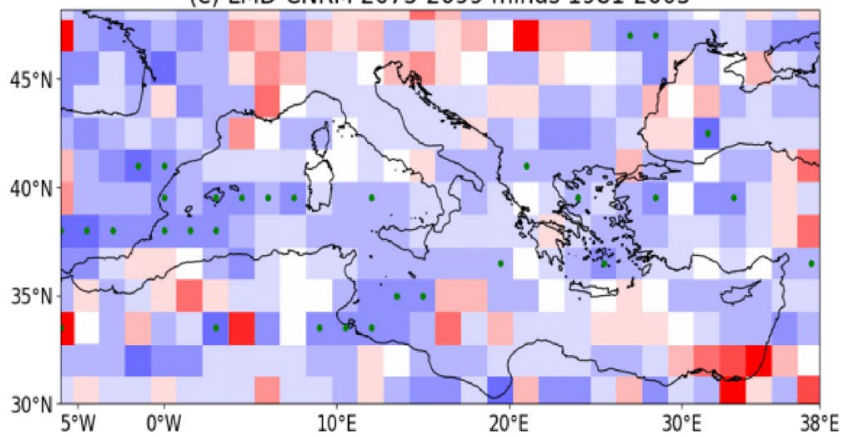

(g) LMD-IPSL 2075-2099 minus 1981-2005

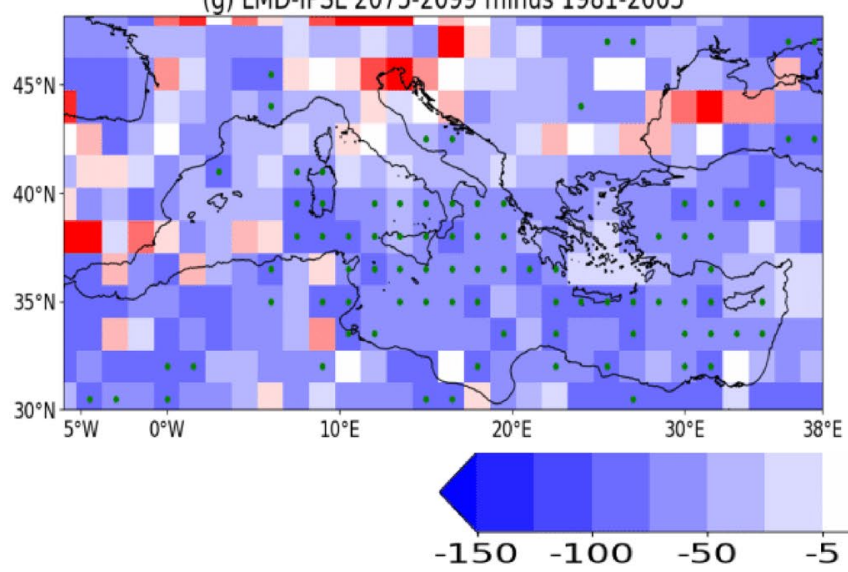

Fig. 9 Spatial distribution of the relative changes (in \%) with respect to the period 1981-2005 of the annual number of cyclone tracks in the period 2075-2099 in the multi-model means (ENSEMBLE, a), ROM (b), EBU-POM (c), CNRM-RCSM4 (d), LMD-CNRM (e), LMD-MPI (f), LMD-IPSL (g) and COSMOMED (h). Green dots in

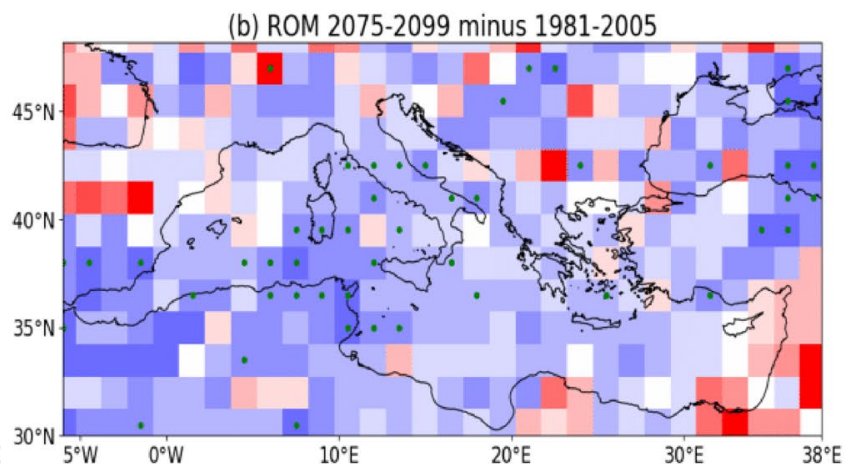

(d) CNRM-RCSM4 2075-2099 minus 1981-2005

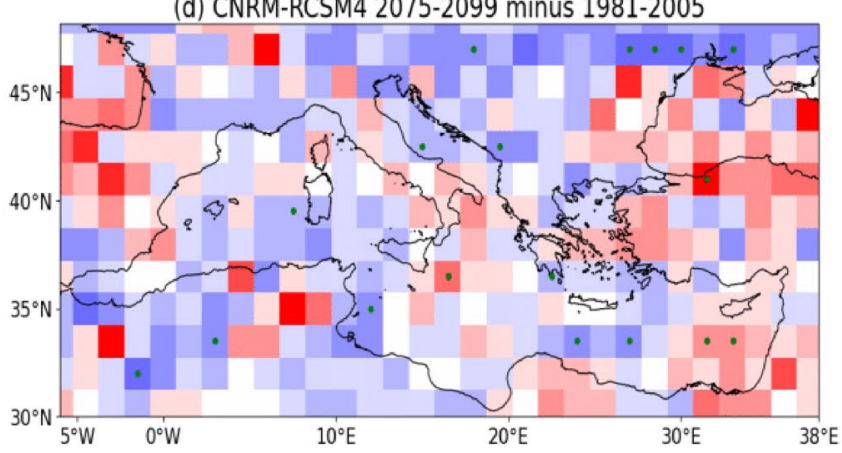

(f) LMD-MPI 2075-2099 minus 1981-2005

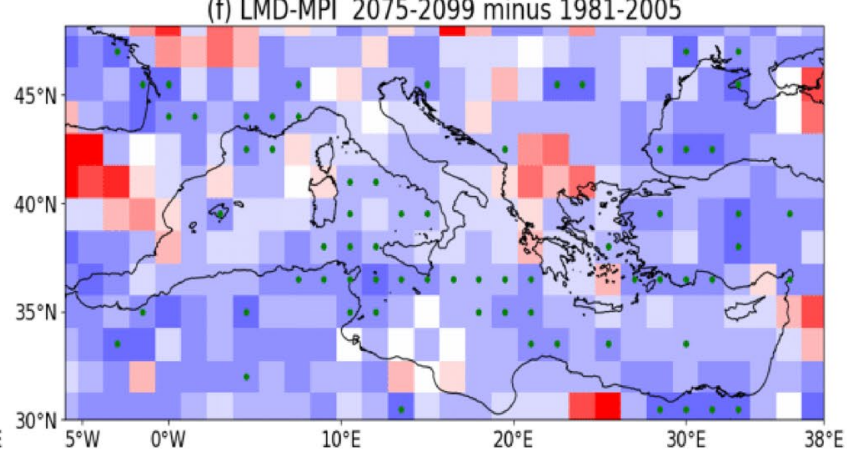

(h) COSMOMED 2075-2099 minus 1981-2005

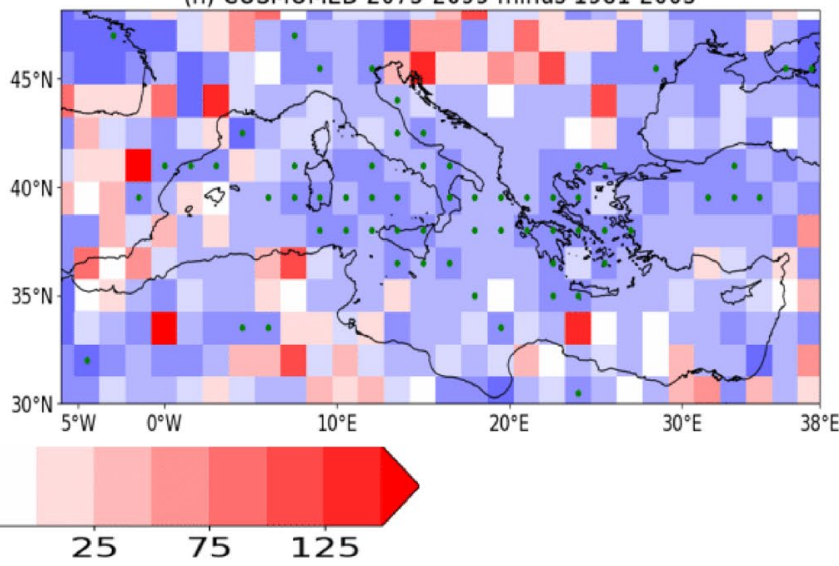

the multi-model means panel (a) shows the cells where the climate change signal is robust among the RCSMs (see the text). Green dots in the panels b-h mark the cells where the difference in the density of tracks between the period 2075-2099 and 1981-2005 is statistically significant with $p<0.05$ 
(a) Cyclogenesis area

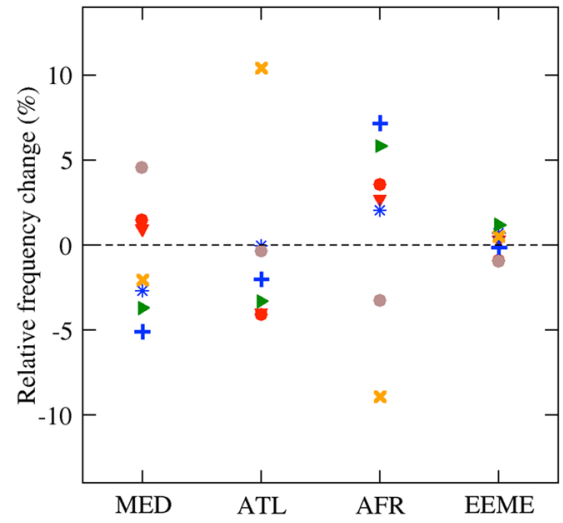

(d) MAX ADR

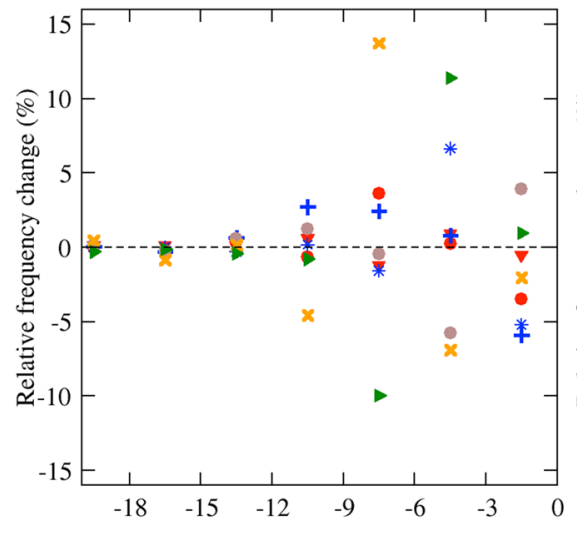

(b) Seasonal cycle

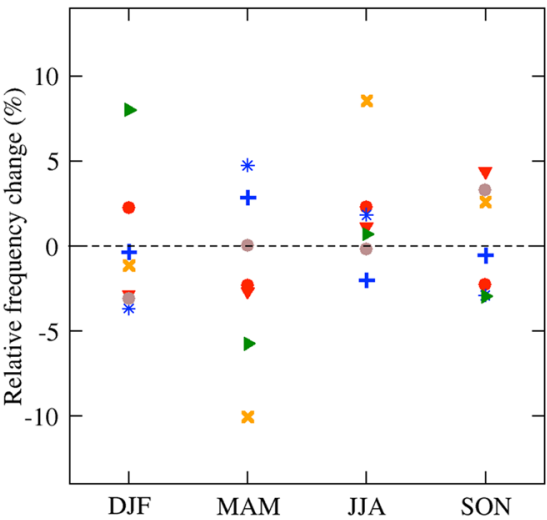

(e) RADIUS

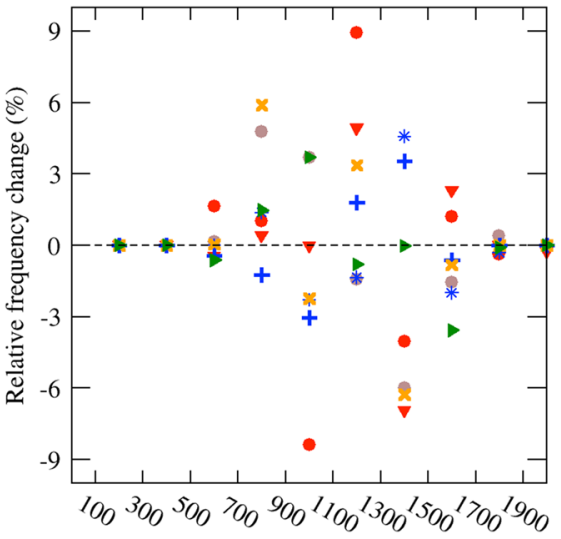

(c) MIN MSLP

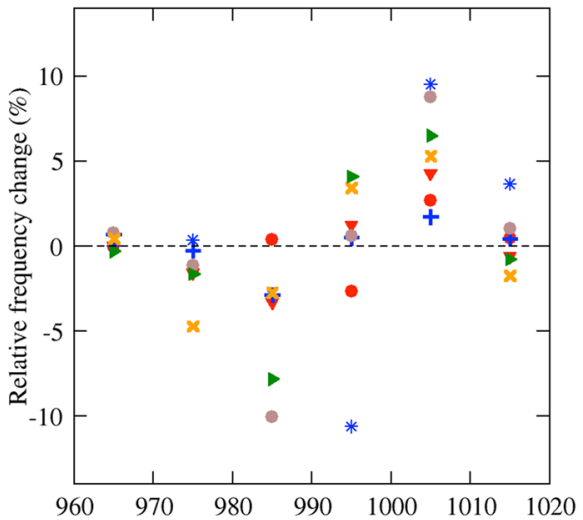

Fig. 10 Changes with respect to the period 1981-2005 in the relative frequency (in \%) of cyclones in function of: a their area of formation, $\mathbf{b}$ the season when the system is detected, $\mathbf{c}$ their lifetime MSLP minimum considering $10 \mathrm{hPa}$ wide bins and covering the range from
960 to $1010 \mathrm{hPa}$, d their lifetime maximum adjusted deepening rate (ADR) considering $3 \mathrm{hPa} / 6 \mathrm{~h}$ wide bins and covering the range from -21 to $0 \mathrm{hPa} / 6 \mathrm{~h}$, e their average radius considering $200 \mathrm{~km}$ wide bins and covering the range from 100 to $1900 \mathrm{~km}$ region (up to 5\% in LMD-CNRM). With the only exception of LMD-IPSL (which shows an increase of up to 10\%) all the other RCSMs project a decrease of the number of cyclones entering the Mediterranean region from the Atlantic (up to $4 \%$ in EBU-POM, Fig. 10a). However, ROM, EBU-POM and LMD-MPI show an increase in the number of cyclones originating inside the Mediterranean region, whereas CNRM-RCSM4 and LMD-CNRM show an increase in the number of cyclones formed over Africa. In winter (DJF), two out of seven RCSMs (EBU-POM and COSMOMED) show an increase in cyclone frequency. CNRM-RCSM4 and LMD-CNRM project an increase of cyclone frequency during spring time (MAM; between 3 and 5\%) while LMDIPSL shows a decrease in the frequency of about $10 \%$. Five out of seven RCSMs show an increase in cyclone frequency during summer (up to 8\% in LMD-IPSL). Only 3(4) out of 7 RCSMs exhibit a decrease (increase) of frequency of cyclones during autumn (SON) with values reaching $3 \%$ (4\%) in COSMOMED (ROM).
A general agreement on the sign of the changes in the minimum lifetime MSLP is observed (Fig. 10c). All RCSMs project an overall decrease in the intensity of cyclones moving through the region. Moreover, the signal observed is statistically significant in 5 out of 7 RCSMs (ROM, LMDCNRM, LMD-IPSL, LMD-MPI and COSMOMED). The models show a relatively low agreement in the case of changes in maximum life-time ADR (Fig. 10d). On the other hand, in the case of mean radius the level of agreement is relatively higher (Fig. 10e). For example, RCSMs laterally forced by CNRM-CM5 (CNRM-RCSM4 and LMD-CNRM) project a shift towards significantly lower values of maximum ADR and higher values of the radius in the range [1300; 1500$] \mathrm{km}$. COSMOMED and LMD-IPSL simulates a significant increase in the frequency of systems in the interval $[-6 ;-3] \mathrm{hPa} / 6 \mathrm{~h}$ and $[-9 ;-6] \mathrm{hPa} / 6 \mathrm{~h}$ respectively, and a decrease of the size of the systems crossing the region. Finally, EBU-POM simulates a significant increase in frequency of the systems in the interval $[-9 ;-6]$ and 
$[-3 ; 0] \mathrm{hPa} / 6 \mathrm{~h}$ and a decrease of the size of systems moving through the region.

To summarize, except for the decrease in the number of cyclone tracks over most of the Western part of Mediterranean region and a general tendency of the systems crossing the region to become shallower, there is no general agreement among RCSMs about the future changes in the cyclone activity in the Eastern basin, genesis areas, seasonality and in some key variables such as adjusted deepening rate. For the mean size five out of seven RCSMs project a statistically significant decrease.

Figure 11 shows the distribution of changes in annual cyclone-related hourly-precipitation. Here, we consider the extended winter season ONDJFM for 2075-2099 and the changes (in \%) with respect to the same season in 1981-2005. In the multi-model-mean a robust climate change signal is observed only in limited areas of the Mediterranean region (Fig. 11a). It is possible to observe an increase over part of the Alps, the central part of Italy and the Adriatic Sea (which coincides with the decrease of cyclone track density shown in Fig. 9a), and the Balkan area. Moreover, a decrease is observed over limited areas of the southern Iberian Peninsula, northern Africa and Levantine basin. Also, in each single RCSM the variations observed are hardly statistically significant and mostly limited to some small areas. LMD-IPSL (Fig. $11 \mathrm{~g}$ ) projects a decrease over most of the eastern part of the Mediterranean Sea (which also coincides with the decrease of cyclone track density observed in Fig. 9g). On the other hand, ROM (Fig. 11b), LMD-CNRM (Fig. 11e), LMD-MPI (Fig. 11f) and COSMOMED (Fig. 11h) project an overall increase over Italy (spatially coherent with the decrease of cyclone track density in these models shown in Fig. 9 b, e, f, g, h). CNRM-RCSM4 (Fig. 11d) and LMDCNRM (Fig. 11e) simulates another increase over part of the Ionian Sea, which corresponds spatially to a previously observed increase of density of tracks (Fig. 9d, e). Moreover, CNRM-RCSM4 (Fig. 11d) also shows a decrease of cyclone-related precipitation, which is coherent with a decrease/increase of density track over the Tyrrhenian/ Levantine basin (Fig. 9d).

RCSMs agree in showing a decrease in the wind speed over part of Western France and around the Pyrenees areas, part of the Ionian Sea, Gulf of Gabes area, Northern Africa and around Cyprus (Fig. 12a). An increase of the wind speed is observed in small areas around Sardinia, Tyrrhenian Sea and Eastern Europe (Fig. 12a). LMD-IPSL (Fig. 12g) projects a significant decrease of cyclonerelated wind speed over most of the eastern Mediterranean Sea (which also coincides with the decrease of both cyclone track density and precipitation observed in Fig. $9 \mathrm{~g}$ and Fig. 11g). On the other hand, ROM, LMD-CNRM and LMD-MPI show a statistically significant increase of the wind speed on the Tyrrehian and part of Italy, which is spatially coherent with the variation of the precipitation previously discussed (Fig. 12b, e, f, respectively).

\section{Discussion with respect to GCM and RCSM characteristics}

In this section we discuss the sources of uncertainty in the characteristics (Sect. 3.1) and in the sign of future changes (Sect. 3.2) of the cyclone activity in the Mediterranean region.

In a recent study, Flaounas et al. (2021a) showed that the dynamics and intensity of the Mediterranean cyclones is influenced by both baroclinic forcing and diabatic processes. In fact, the more a cyclone is baroclinically driven, the less diabatic processes play a role to its development and intensity and vice versa. As a result, physical parameterization might play an important role in cyclone intensity differences among the models only for a fraction of the systems. As a token of this fraction, Galanaki et al. (2016) showed that only about a third of intense cyclones may produce deep convection in their center. For the rest of the cyclones where baroclinic forcing is important, the dynamics and intensity of the cyclone will depend on the driving GCM and more precisely on the dynamical characteristics of the intruding troughs that trigger cyclogenesis.

This explains the differences in the density of tracks between LMD-MPI (Fig. 2g) and LMD-IPSL (Fig. 2h) or the strong negative bias observed in the cyclone frequency $(-14 \%)$ in December in LMD-IPSL (Fig. 4b). The IPSL GCM is, in fact, characterized by anticyclonic biases, which results in an overestimation of the blocking in the Northern Atlantic and reduced cyclone activity in the Mediterranean region (Tuel et al. 2020).

Some additional factors can explain the spread among RCSMs and biases observed in Sect. 3.1. One of these is represented by the regional model physics. In fact, the physics of the model and the resulting SST biases and surface temperature patterns (Darmaraki et al. 2019; Soto-Navarro et al. 2020) influences the air-sea heat exchanges and therefore partially the cyclogenesis processes together with the vertical stability of the air column and thus the convection and related precipitation. For example, ROM is characterized by an overall cold bias with respect to satellite SST of approximately $1.1{ }^{\circ} \mathrm{C}$ (Darmaraki et al. 2019) and this explains the underestimation of the precipitation observed over most of the Mediterranean Sea (Fig. 8b). The other factors are represented by a group of RCSM internal features such as the ratio between the size of the relaxation zone at the boundary and the lateral coupling frequency ( $\mathrm{Li}$ et al. 2021), the RCSM internal variability (Sanchez-Gomez 
(a) CYCL PREC 2075-2099 minus 1981-2005

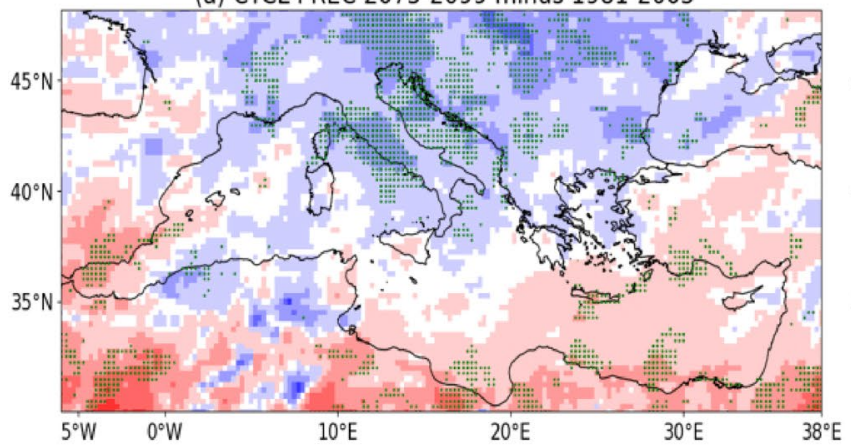

(c) EBU-POM HOURLY CYCL PREC 2075-2099 minus 1981-2005

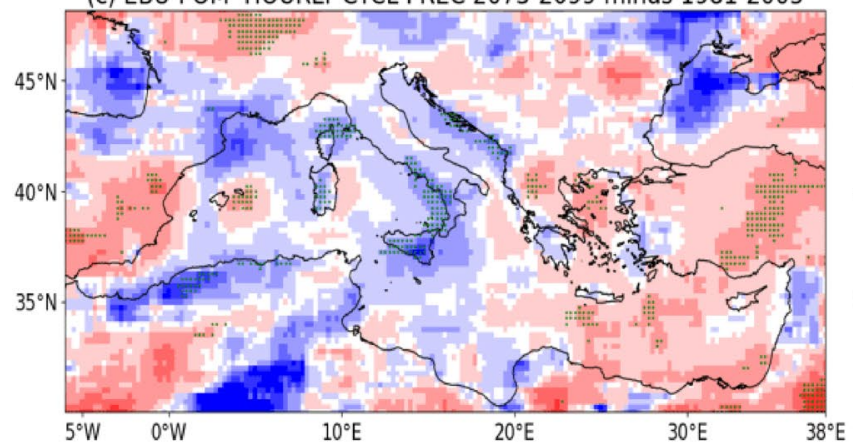

(e) LMD-CNRM HOURLY CYCL PREC 2075-2099 minus 1981-2005

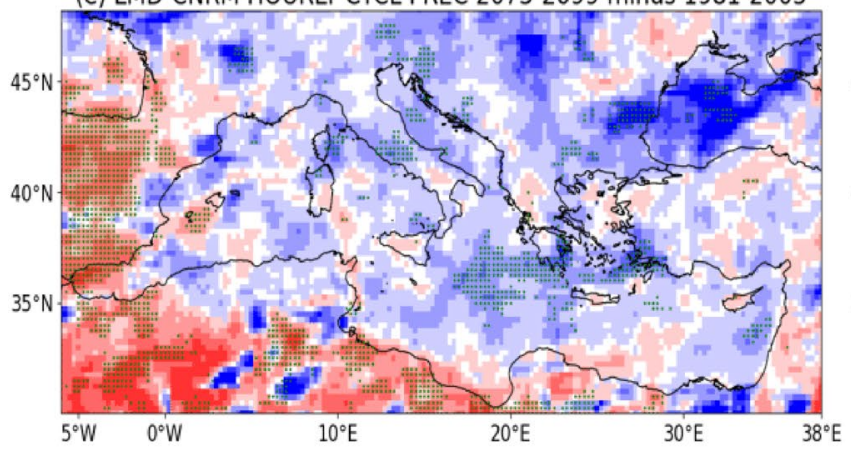

(g) LMD-IPSL HOURLY CYCL PREC 2075-2099 minus 1981-2005

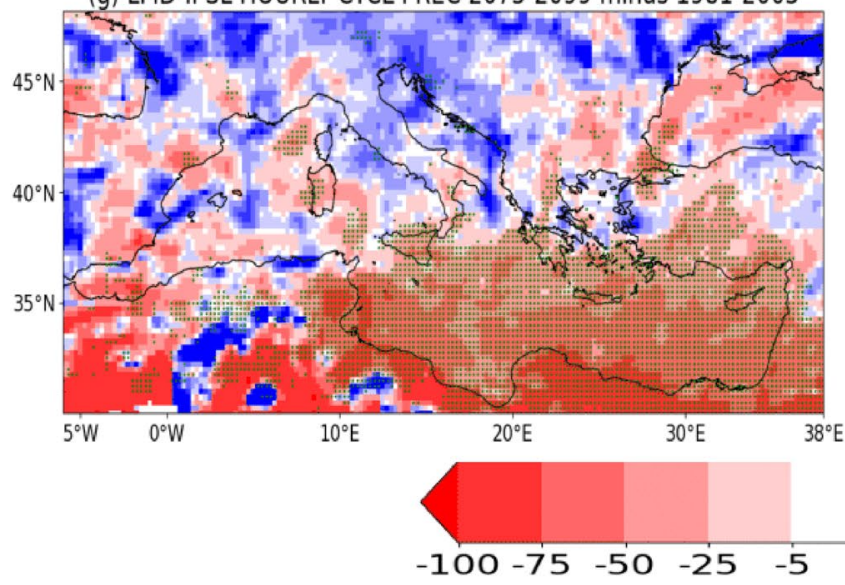

(b) ROM HOURLY CYCL PREC 2075-2099 minus 1981-2005

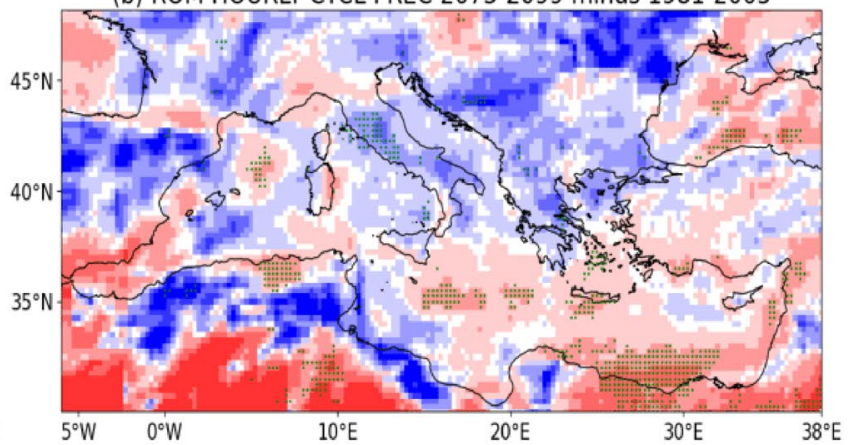

(d) CNRM-RCSM4 HOURLY CYCL PREC 2075-2099 minus 1981-2005

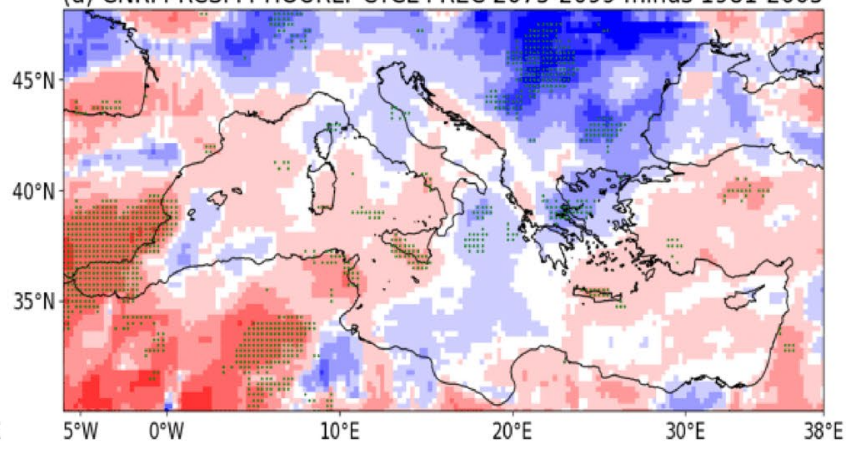

(f) LMD-MPI HOURLY CYCL PREC 2075-2099 minus 1981-2005

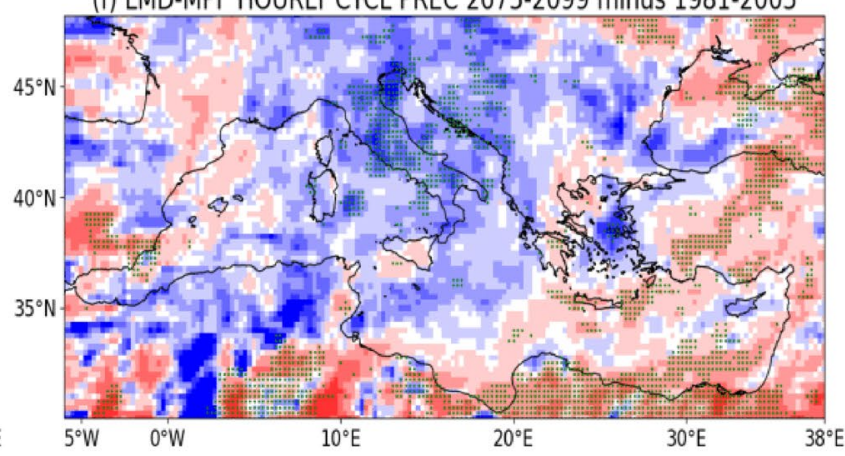

(h) COSMOMED HOURLY CYCL PREC 2075-2099 minus 1981-2005

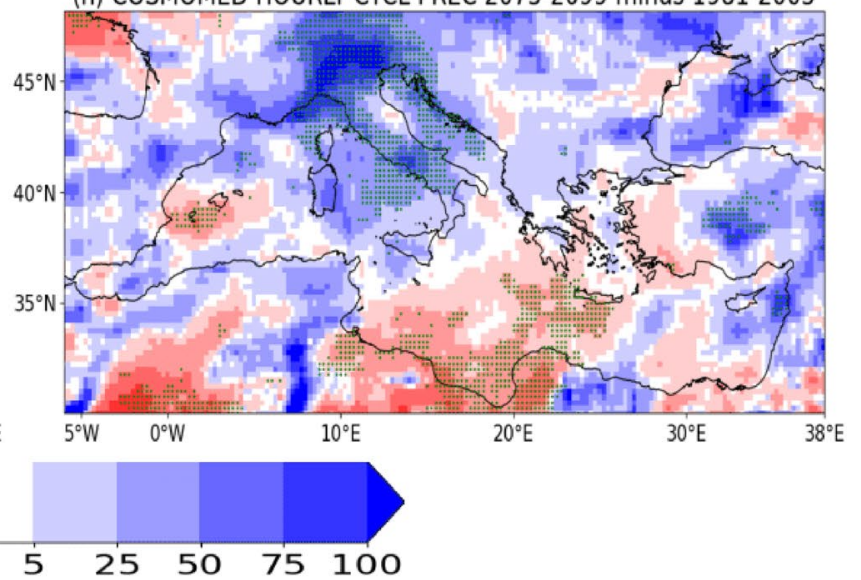

Fig. 11 Same as Fig. 9 but for the hourly precipitation change (in \%) 
(a) CYCL WIND SPEED 2075-2099 minus 1981-2005

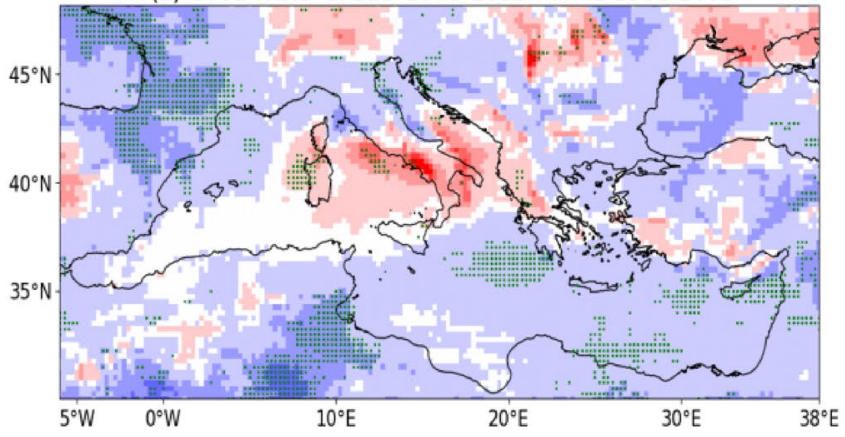

(c) EBU-POM HOURLY CYCL WIND SPEED 2075-2099 minus 1981-2005

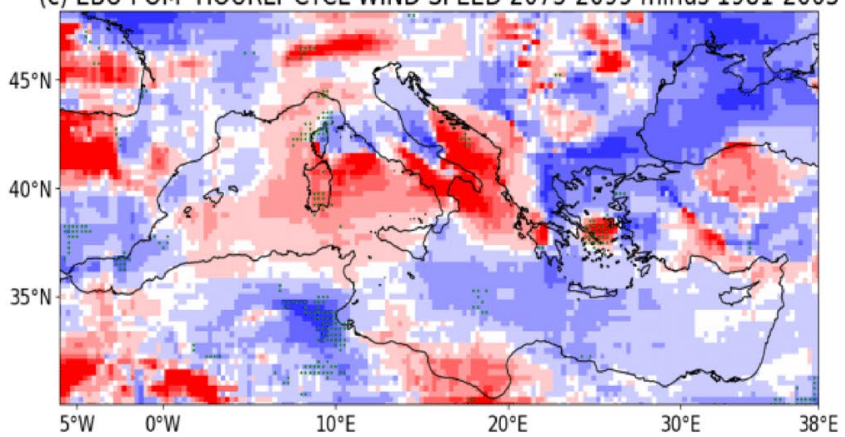

(e) LMD-CNRM HOURLY CYCL WIND SPEED 2075-2099 minus 1981-2005

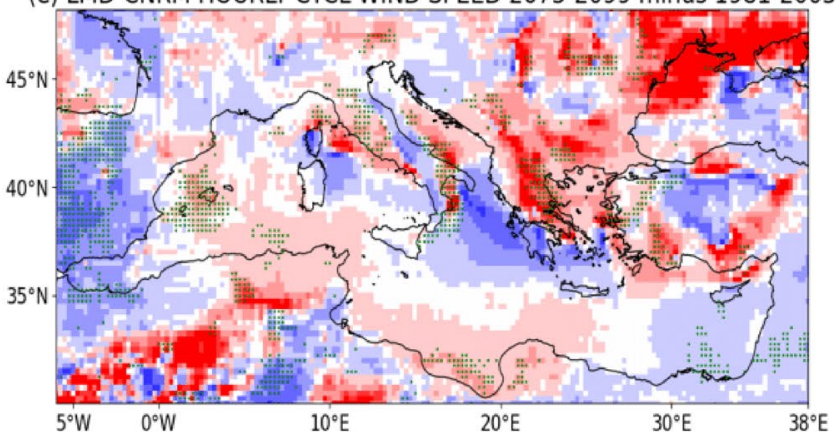

(g) LMD-IPSL HOURLY CYCL WIND SPEED 2075-2099 minus 1981-2005

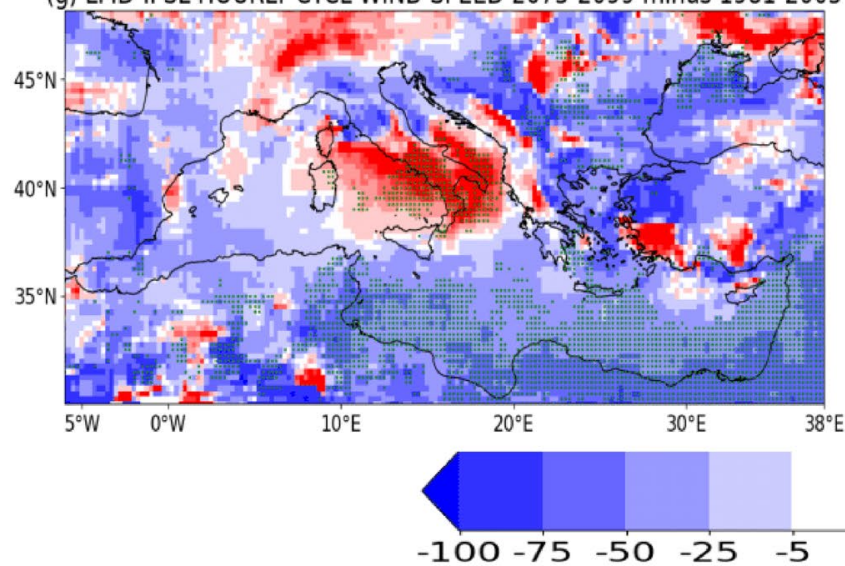

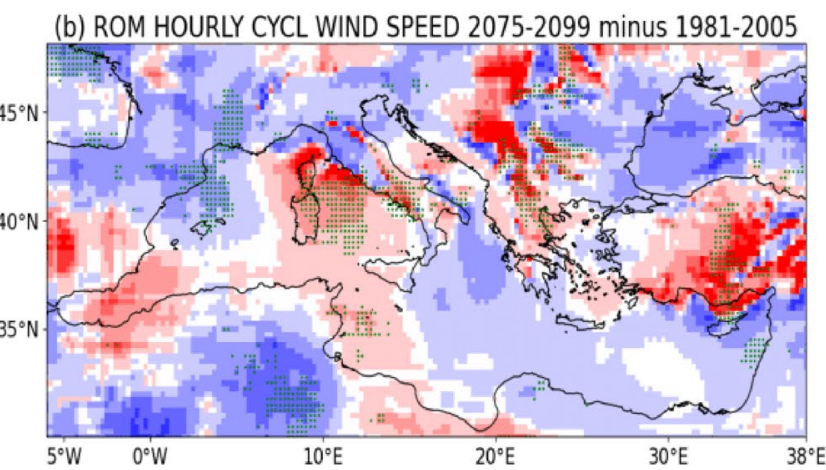

(d) CNRM-RCSM4 HOURLY CYCL WIND SPEED 2075-2099 minus 1981-2005

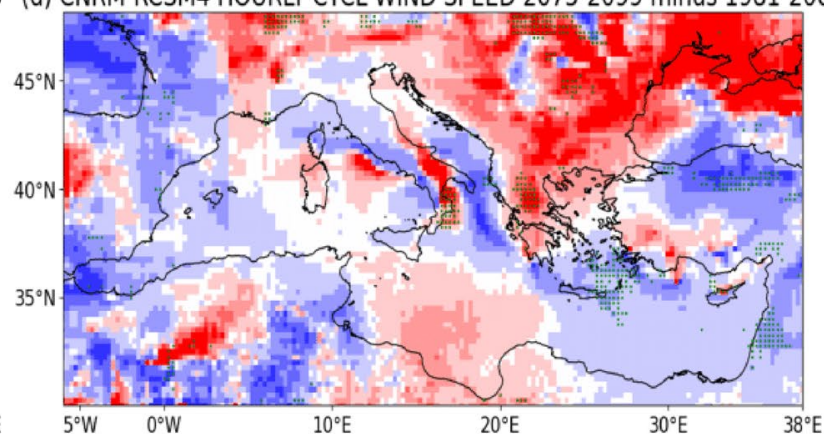

(f) LMD-MPI HOURLY CYCL WIND SPEED 2075-2099 minus 1981-2005

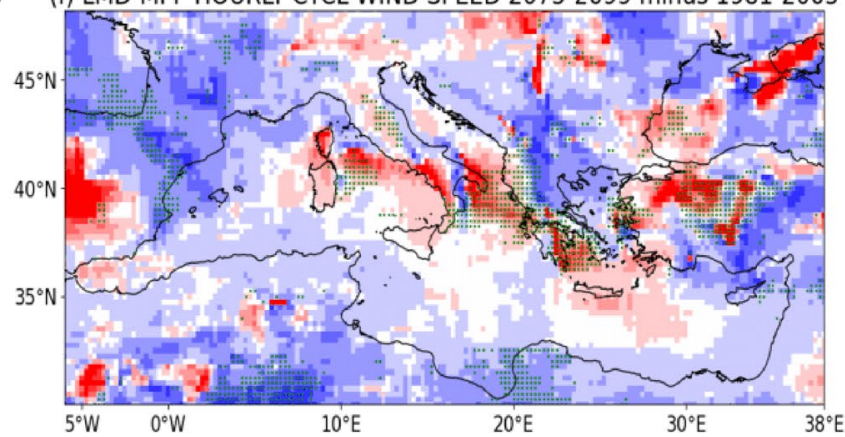

(h) COSMOMED HOURLY CYCL WIND SPEED 2075-2099 minus 1981-2005

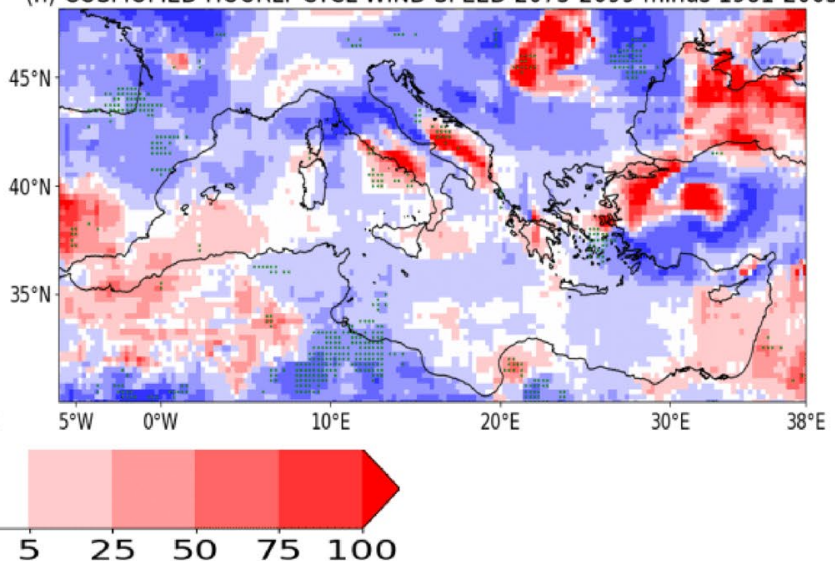

Fig. 12 Same as Fig. 11 but for the wind speed change (in \%)

and Somot 2018) and the different domain size of the atmospheric module. For example, if a cyclone arriving from the Atlantic moves fast it would be able to cross the relaxation zone without leaving a footprint. This cyclone would therefore be completely missed or at least weakened close to the lateral boundaries, influencing 
the observed density of tracks and related precipitation. The so-called Regional Climate Model (RCM) internal variability could represent an additional mechanism driving the eastward increase of the spread among RCSMs observed in Fig. 2. In fact Sanchez-Gomez and Somot (2018) have shown that in the Mediterranean region, using the same boundary conditions and RCM numerical setting but slightly different initial conditions, the spread affecting the cyclone activity among different runs done with the same RCM is higher in the Eastern part with respect to the Western part of the region. This means that the eastward increase of spread among RCSMs density of tracks, mainly around the Cyprus area, could be driven by the internal variability of each member of the ensemble, further amplifying the differences eventually related to the factors discussed above. Finally, the different size of the domains could provide a clue of why for example ROM and COSMOMED, whose domains are the largest (Fig. 1), are characterized by higher percentages of Atlantic cyclones compared, for example, to LMD which has the smallest domain (Fig. 1) and the highest percentage of cyclones formed in the Mediterranean region (Sect. 3.1).

The importance of the driving GCM can also explain the differences between LMD-MPI (Fig. 11f and Fig. 12f) and LMD-IPSL (Fig. 11g and Fig. 12g) in the projected changes for the precipitation and wind speed. The former projects a decrease of the density of tracks and an increase of hourly precipitation and wind speed over Central Italy, the latter a decrease of the cyclone track density and associated precipitation and wind speed over the Eastern basin. Further evidence of the importance of the driving GCM is represented by the comparison of the projections of CNRM-RCSM4 and LMD-CNRM. Both tend to show at the end of the twenty-first century an increase in the density of tracks over the Ionian and Levantine basin (Fig. 9d-e) together with an increase in the precipitation over the Ionian Sea (Fig. 11d-e) and a decrease(increase) of the wind speed over the northern(southern) Ionian (Fig. 12d-e). On the other hand, the two simulations differ in the terms of climate change signal sign and significance in the Levantine basin, with CNRM-RCSM4 showing a decrease in the precipitation and wind speed over the area (Fig. 11d and Fig. 12d) and LMD-CNRM projecting an increase in the precipitation over Cyprus and an increase of the wind speed along southern Anatolian coastlines (Fig. 11e and Fig. 12e).This further supports the importance of internal physics of each RCSM in modulating the climate change signal imposed by the driving GCM.

\section{Summary and conclusions}

Cyclones are an important component of the atmospheric circulation in the Mediterranean region, influencing the energy balance and water budget of the regional climate system. They also largely determine the timing and intensity of extreme events in the area (Nissen et al. 2010; Reale and Lionello 2013; Flaounas et al. 2016, 2017, 2021b; Lionello et al. 2019, 2020; Hochman et al. 2021).

Here, we use a set of 7 state-of-the-art fully-coupled Regional Climate System Models (RCSMs) simulations from the Med-CORDEX initiative (Ruti et al. 2016; Darmaraki et al. 2019) to analyze cyclone activity and associated precipitation and wind fields over the Mediterranean region for present day (1981-2005) and future projection (2075-2099; RCP8.5).

The RCSMs used here are able to capture the main characteristics of cyclone activity in the Mediterranean region in present-day climate conditions and related precipitation and wind patterns, despite some quantitative differences such as an overestimation (underestimation) of number of tracks over Northern Africa and Cyprus area (Gulf of Genoa and Iberian Peninsula), of the precipitation over the mountain chains (over part of the Adriatic Sea, the Balkan area and Aegean Sea) and of the wind flowing through the Otranto strait (over the Aegean Sea). However, no dramatic biases with respect to ERA5 reanalysis have been found. We have therefore considered these stateof-art RCSMs as plausible representations of cyclone activity in the Mediterranean region in present and future scenarios.

Our RCSMs ensemble projects for the end of the twentyfirst century a robust (according to the definition introduced in Sect. 3.2) decrease of the number and intensity of cyclone crossing the central part of Italy, Tyrrhenian Sea, part of the Anatolian Peninsula, Balkan area and part of Northern Africa and an overall weakening of the systems crossing the region. We also found a robust increase in the cyclone-related precipitation and wind intensity in the central part of the Mediterranean region. Conversely, we observed a change of opposite sign in both variables in the south eastern part of the region. Both signals are spatially coincident with the decrease of the number of tracks observed before. Our ensemble projects an overall decrease in total accumulated precipitation in winter over most of the Mediterranean region (not shown here). This means that, using the decomposition technique adopted in Zappa et al. 2015, the decrease of the accumulated precipitation in winter over most of the Mediterranean will be driven by the decrease in the number of cyclones crossing the area (Fig. 9) and will be only partially compensated by the increase in the intensity of the rainy events associated with each cyclone (Fig. 11). In the Eastern part of the region the drier conditions observed 
in winter will be driven by both decrease in the number of cyclones and intensity of each rainy event. These findings are in agreement with the findings of Zappa et al. (2015), which used 17 CMIP5 models to show that the northern part of the Mediterranean region $\left(40^{\mathrm{u}} \mathrm{N}-45^{\circ} \mathrm{N}\right)$ is projected to have a decrease of the number of Mediterranean cyclones compensated by an increase in the amount of precipitation generated by each system and an overall decrease of cyclone-related precipitation in the Levantine area, which further amplifies the decrease of precipitation due to the reduction in the number of cyclones crossing that region (Hochman et al. 2020). Two of them (CMCCCM and IPSL-CM5A-MR) are used as driving GCMs in this study. Additionally, the storyline approach adopted in Zappa et al. (2017) further supports the cyclone-related precipitation response to climate change observed in Fig. 11 and the importance of the driving GCM in explaining the signal observed. According to the classification discussed in Zappa et al. (2017), MPI-ESM-LR, MPI-ESM-MR, IPSL-CM5-MR, CMCC-CM are associated with high tropical amplification and weak polar stratospheric vortex. Conversely CNRM-CM5 is associated with low tropical amplification and strong stratospheric vortex. In the first case the storyline involves an overall reduction in the precipitation over the Eastern Mediterranean, as is shown Fig. 11b, c, f, g, h, linked to a persistent anticyclonic pattern insisting over the area. In the second case the storyline shows a large reduction of the precipitation over the Iberian peninsula as also shown in this case in Fig. 11d, e. It is relevant to note that, unfortunately, only two out of the four Zappa's storylines have been explored in Med-CORDEX using RCSMs, leading to unexplored possible futures.

Differences among the RCSMs emerge in the sign and magnitude of the changes concerning the cyclone's area of origin, their seasonality, deepening rate and associated precipitation and wind speed. The differences observed have been assessed with respect to different plausible sources, such as the driving GCM, the internal variability and physics of each RCSM and the domain size of the atmospheric module. The magnitude of the projected changes (also with RCSMs driven by the same GCM) varies considerably across models, showing the importance of the model physics representation in modulating the projected changes driven by GCM, especially in winter (e.g. Akperov et al. 2019).

Our results indicate that there are still important uncertainties in RCSM-based projections of changes in cyclone characteristics over the Mediterranean region. This uncertainty needs to be fully characterized through the use of large model ensembles sharing a consistent simulation protocol able to cover the whole climate change spread. Our results are based on the largest available, but still relatively small set of RCSMs. Another possible approach to better characterize the uncertainty in the future evolution of the Mediterranean cyclone activity would be a thorough and process-relevant sub-sampling of the whole a-priori ensemble to determine self-consistent, region-relevant and plausible future pathways of the regional climate system for a given phenomenon following the aforementioned storyline approach (Zappa and Shepherd 2017; Shepherd 2019).

Future work will include a larger set of simulations currently being produced under the Med-CORDEX framework to better characterize the uncertainty, but also to better understand the driving mechanisms of the projected changes in cyclone characteristics.

Acknowledgements $\mathrm{M}$. Reale has been supported in this work by OGS and CINECA under HPC-TRES award number 2015-07 and by the project FAIRSEA (Fisheries in the Adriatic Region—a Shared Ecosystem. Approach) funded by the 2014-2020 Interreg V-A Italy-Croatia CBC Programme (Standard project ID 10046951). A. Hochman is funded by the German Helmholtz Association ("Changing Earth" program). D. V. Sein worked in the framework of the state assignment of the Ministry of Science and Higher Education of Russia (theme No. 01282021-0014). This work is part of the Med-CORDEX initiative (www. medcordex.eu) supported by the HyMeX programme (www.hymex. org), and a contribution to the COST MEDCYCLONES: European Network for Mediterranean Cyclones in weather and climate. The simulations used in this work were downloaded from the Med-CORDEX database (www.medcordex.eu). S. Somot acknowledges the support of the Meteo-France supercomputer center to achieve the simulations and warmly thanks F. Sevault for developing CNRM-RCSM4 and running the coupled simulations. L. Li acknowledges the French GENCI and IDRIS for the allocation of computing resources. The authors acknowledge JG Pinto from KIT for his useful feedback on the preliminary version of this manuscript.

Open Access This article is licensed under a Creative Commons Attribution 4.0 International License, which permits use, sharing, adaptation, distribution and reproduction in any medium or format, as long as you give appropriate credit to the original author(s) and the source, provide a link to the Creative Commons licence, and indicate if changes were made. The images or other third party material in this article are included in the article's Creative Commons licence, unless indicated otherwise in a credit line to the material. If material is not included in the article's Creative Commons licence and your intended use is not permitted by statutory regulation or exceeds the permitted use, you will need to obtain permission directly from the copyright holder. To view a copy of this licence, visit http://creativecommons.org/licenses/by/4.0/.

\section{References}

Akhtar N, Brauch J, Dobler A, Béranger K, Ahrens B (2014) Medicanes in an ocean-atmosphere coupled regional climate model. Nat Hazards Earth Syst Sci 14:2189-2201. https://doi.org/10. 5194/nhess-14-2189-2014

Akperov M, Rinke A et al (2019) Future projections of cyclone activity in the Arctic for the 21st century from regional climate models (Arctic-CORDEX). Global Planet Change. https://doi.org/10. 1016/j.gloplacha.2019.103005

Alpert P, Neeman BU, Shay-El Y (1990) Climatological analysis of Mediterranean Cyclones using ECMWF data. Tellus 42A:65-77

Buzzi A, Davolio S, Fantini M (2020) Cyclogenesis in the lee of the Alps: a review of theories. Bull Atmos Sci Technol 1:433-457. https://doi.org/10.1007/s42865-020-00021-6 
Campins J, Genovés A, Picornell MA, Jansà A (2010) Climatology of Mediterranean cyclones using the ERA-40 dataset. Int J Climatol. https://doi.org/10.1002/joc.2183

Cavicchia L, von Storch H, Gualdi S (2014) Mediterranean tropicallike cyclones in present and future climate, J Climate 27(19): 7493-7501. Retrieved Mar 25, 2021, from https://journals.amets oc.org/view/journals/clim/27/19/jcli-d-14-00339.1.xml

Cavicchia L, Gualdi S, Sanna A, Oddo P (2015) The regional ocean atmosphere coupled model COSMONEMO_MFS. CMCC Research Papers. Italy, Bologna, pp 1-22. https://www.cmcc.it/ wp-content/uploads/2015/04/rp0254-csp-04-2015.pdf

Conte D, Gualdi S, Lionello P (2020) Effect of model resolution on intense and extreme precipitation in the Mediterranean region. Atmosphere 11(7):699. https://doi.org/10.3390/atmos1107069

Darmaraki S, Somot S, Sevault F, Nabat P, Cabos W, Cavicchia L, Djurdjevic V, Li L, Sannino G, Sein D (2019) Future evolution of marine heat waves in the Mediterranean sea. Clim Dyn 53(34):1371-1392. https://doi.org/10.1007/s00382-019-04661-z

Djurdjevic V, Rajkovic B (2008) Verification of a coupled atmosphere-ocean model using satellite observations over the Adriatic Sea. Ann Geophys 26(7):1935-1954. https://doi.org/10.5194/ angeo-26-1935-2008

Donat M, Leckebusch G et al (2011) Future changes in European winter storm losses and extreme wind speeds inferred from GCM and RCSM multi-model simulations. Nat Hazards Earth Syst Sci 11:1351-1370. https://doi.org/10.5194/ nhess-11-1351-2011

Dufresne JL, Foujols MA, Denvil S et al (2013) Climate change projections using the IPSL-CM5 earth system model: from CMIP3 to CMIP5. Clim Dyn 40:2123-2165. https://doi.org/10.1007/ s00382-012-1636-1

Fantini A, Raffaele F, Torma C et al (2018) Assessment of multiple daily precipitation statistics in ERA-interim driven med-CORDEX and EURO-CORDEX experiments against high resolution observations. Clim Dyn 51:877. https://doi.org/10.1007/ s00382-016-3453-4

Flaounas E, Drobinski P, Bastin S (2013) Dynamical downscaling of IPSL-CM5 CMIP5 historical simulations over the Mediterranean: benefits on the representation of regional surface winds and cyclogenesis. Clim Dyn 40:2497-2513. https://doi.org/10. 1007/s00382-012-1606-7

Flaounas E, Di Luca A, Drobinski P, Mailler S, Arsouze T, Bastin S, Beranger K, Lebeaupin Brossier C (2016) Cyclones contribution to the Mediterranean Sea water budget. Clim Dynam. https://doi. org/10.1007/s00382-015-2622-1

Flaounas E, Kotroni V, Lagouvardos K, Gray S, Rysman JF, Claud C (2017) Heavy rainfall in Mediterranean cyclones, part I: contribution of deep convection and warm conveyor belts. Clim Dynam. https://doi.org/10.1007/s00382-017-3783-x

Flaounas E, Kelemen FD, Wernli H, Gaertner MA, Reale M, SanchezGomez E, Lionello P, Calmanti S, Podrascanin Z, Somot S, Akhtar N, Romera R, Conte D (2018) Assessment of an ensemble of ocean-atmosphere coupled and uncoupled regional climate models to reproduce the climatology of Mediterranean cyclones. Clim Dyn 51:1023-1040. https://doi.org/10.1007/s00382-016-3398-7

Flaounas E, Gray SL, Teubler F (2021a) A process-based anatomy of Mediterranean cyclones: from baroclinic lows to tropical-like systems. Weather Clim Dynam 2:255-279. https://doi.org/10.5194/ wcd-2-255-2021

Flaounas E, Davolio S, Raveh-Rubin S, Pantillon F, Miglietta MM, Gaertner MA, Hatzaki M, Homar V, Khodayar S, Korres G, Kotroni V, Kushta J, Reale M, Ricard D (2021b) Mediterranean cyclones: current knowledge and open questions on dynamics, prediction, climatology and impacts. Weather Clim Dynam Discuss. https://doi.org/10.5194/wcd-2021-55 (preprint, in review)
Gaertner MÁ, González-Alemán JJ, Romera R et al (2018) Simulation of medicanes over the Mediterranean Sea in a regional climate model ensemble: impact of ocean-atmosphere coupling and increased resolution. Clim Dyn 51:1041-1057. https://doi.org/10. 1007/s00382-016-3456-1

Galanaki E, Flaounas E, Kotroni V, Lagouvardos K, Argiriou A (2016) Lightning activity in the Mediterranean: quantification of cyclones contribution and relation to their intensity. Atmos Sci Lett 17:510-516. https://doi.org/10.1002/asl.685

Giorgetta MA et al (2013) Climate and carbon cycle changes from 1850 to 2100 in MPI-ESM simulations for the coupled Model Intercomparison Project phase 5. J Adv Model Earth Syst 5(3):572-597. https://doi.org/10.1002/jame.20038

Giorgi F, Jones C, Asrar GR (2009) Addressing climate information needs at the regional level: the CORDEX framework. World Meteorol Organ (WMO) Bull 58.3:175

Hersbach H, Bell B, Berrisford P et al (2020) The ERA5 global reanalysis. Q J R Meteorol Soc 146:1999-2049. https://doi.org/10. 1002/qj.3803

Hochman A, Harpaz T, Saaroni H, Alpert P (2018a) Synoptic classification in 21 st century CMIP5 predictions over the Eastern Mediterranean with focus on cyclones. Int J Climatol 38(3):1476-1483. https://doi.org/10.1002/joc.5260

Hochman A, Harpaz T, Saaroni H, Alpert P (2018b) The seasons' length in 21st century CMIP5 projections over the Eastern Mediterranean. Int J Climatol 38(6):2627-2637. https://doi.org/10. 1002/joc. 5448

Hochman AA, Kunin P et al (2020) The dynamics of cyclones in the twenty-first century: the Eastern Mediterranean as an example. Clim Dyn 54:561-574. https://doi.org/10.1007/ s00382-019-05017-3

Hochman A, Marra F, Messori G, Pinto JG, Raveh-Rubin S, Yosef Y, Zittis G (2021) ESD reviews: extreme weather and societal impacts in the eastern Mediterranean. Earth Syst Dyn Discuss. https://doi.org/10.5194/esd-2021-55 (Preprint, in review)

Hoskins BJ, Hodges KI (2019a) The annual cycle of northern hemisphere storm tracks. Part I: seasons. J Clim 32(6):1743-1760. https://doi.org/10.1175/JCLI-D-17-0870.1

Hoskins BJ, Hodges KI (2019b) The annual cycle of northern hemisphere storm tracks. Part II: regional detail. J Clim 32.6:17611775. https://doi.org/10.1175/JCLI-D-17-0871.1

IPCC (2014) Climate Change 2014: synthesis report. Contribution of working groups I, II and III to the fifth assessment report of the intergovernmental panel on climate change

Kelley C, Ting M, Seager R, Kushnir Y (2012) Mediterranean precipitation climatology, seasonal cycle, and trend as simulated by CMIP5. Geophys Res Lett 39:L21703. https://doi.org/10. 1029/2012GL053416

Kouroutzoglou J, Flocas HA, Keay K, Simmonds I, Hatzaki M (2010) Climatological aspects of explosive cyclones in the Mediterranean. Int J Climatol. https://doi.org/10.1002/joc.2203

Kouroutzoglou J, Flocas HA, Simmonds I et al (2011) Assessing characteristics of Mediterranean explosive cyclones for different data resolution. Theor Appl Climatol 105:263-275. https://doi. org/10.1007/s00704-010-0390-8

L'Hévéder B, Li L, Sevault F et al (2013) Interannual variability of deep convection in the Northwestern Mediterranean simulated with a coupled AORCM. Clim Dyn 41:937-960. https://doi.org/ 10.1007/s00382-012-1527-5

Li S, Li L, Le Treut H (2021) An idealized protocol to assess the nesting procedure in regional climate modelling. Int J Climatol 41:1246-1263. https://doi.org/10.1002/joc.6801

Lionello P, Giorgi F (2007) Winter precipitation and cyclones in the Mediterranean region: future climate scenarios in a regional simulation. Adv Geosci 12(12):153-153 
Lionello P, Dalan F, Elvini E (2002) Cyclones in the Mediterranean region: the present and the doubled $\mathrm{CO} 2$ climate scenarios. Clim Res 22:147-159. https://doi.org/10.3354/cr022147

Lionello $\mathrm{P}$, Bhend J, Buzzi $\mathrm{A}$, Della-Marta $\mathrm{PM}$, Krichak $\mathrm{S}$, Jansà A, Maheras P, Sanna A, Trigo IF, Trigo R (2006) Cyclones in the Mediterranean region: climatology and effects on the environment. In: Lionello P, Malanotte-Rizzoli P, Boscolo R (eds) Mediterranean climate variability. Elsevier (NETHERLANDS), Amsterdam, pp 325-372

Lionello P, Abrantes F, Congedi L, Dulac F, Gacic M, Gomis D et al (2012) Introduction: Mediterranean climate: background information. In: Lionello P (ed) The climate of the Mediterranean region. From the past to the future. Elsevier (NETHERLANDS), Amsterdam, pp XXXV-IXXX (ISBN:9780124160422)

Lionello P, Trigo IF, Gil V, Liberato ML, Nissen KM, Pinto JG, Raible CC, Reale M, Tanzarella A, Trigo RM, Ulbrich S, Ulbrich U (2016) Objective climatology of cyclones in the Mediterranean region: a consensus view among methods with different system identification and tracking criteria. Tellus A 68:29391. https:// doi.org/10.3402/tellusa.v68.29391

Lionello P, Conte D, Reale M (2019) The effect of cyclones crossing the Mediterranean region on sea level anomalies on the Mediterranean Sea coast. Nat Hazards Earth Syst Sci 19(7):1541-1564

Lionello P, Barriopedro D, Ferrarin D, Nicholls CRJ, Orlic M, Raicich F, Reale M, Umgiesser G, Vousdoukas M, Zanchettin D (2020) Extremes floods of Venice: characteristics, dynamics, past and future evolution. Nat Hazards Earth Syst Sci Discuss. https://doi. org/10.5194/nhess-2020-359 (in review)

Maheras P, Flocas H, Patrikas I, Anagnostopoulou C (2001) A 40 year objective climatology of surface cyclones in the Mediterranean region: spatial and temporal distribution. Int J Climatol 21:109-130

Neu U, Akperov MG, Bellenbaum N, Benestad R, Blender R, Caballero R, Cocozza A, Dacre HF, Feng Y, Fraedrich K, Grieger J, Gulev S, Hanley J, Hewson T, Inatsu M, Keay K, Kew SF, Kindem I, Leckebusch GC, Liberato MLR, Lionello P, Mokhov II, Pinto JG, Raible CC, Reale M, Rudeva I, Schuster M, Simmonds I, Sinclair M, Sprenger M, Tilinina ND, Trigo IF, Ulbrich S, Ulbrich U, Wang XL, Wernli H (2013) IMILAST-a community effort to intercompare extratropical cyclone detection and tracking algorithms: assessing method-related uncertainties. Bull Am Met Soc 94:529-547. https://doi.org/10.1175/BAMS-D-11-00154.1

Nissen KM, Leckebusch GC, Pinto JC, Renggli D, Ulbrich S, Ulbrich U (2010) Cyclones causing wind storms in the Mediterranean: characteristics, trends and links to large-scale patterns. Nat Hazard 10:1379-1391

Nissen KM, Leckebusch GC, Pinto JC, Ulbrich U (2014) Mediterranean cyclones and windstorms in a changing climate. Reg Environ Change 14:1873. https://doi.org/10.1007/s10113-012-0400-8

Pinto JG, Ulbrich S, Economou T, Stephenson DB, Karremann MK, Shaffrey LC (2016) Robustness of serial clustering of extratropical cyclones to the choice of tracking method. Tellus a: Dyn Meteorol Oceanogr 68(1):32204

Raible CC, Ziv B, Saaroni H et al (2010) Winter synoptic-scale variability over the Mediterranean Basin under future climate conditions as simulated by the ECHAM5. Clim Dyn 35:473-488. https://doi.org/10.1007/s00382-009-0678-5

Reale M, Lionello P (2013) Synoptic climatology of winter intense precipitation events along the Mediterranean coasts. Nat Hazard 13(7):1707-1722

Reale M, Liberato MLR, Lionello P, Pinto JC, Salon S, Ulbrich S (2019) A global climatology of explosive cyclones using a multitracking approach. Tellus a: Dyn Meteorol Oceanogr 71:1. https:// doi.org/10.1080/16000870.2019.1611340

Reale M, Giorgi F, Solidoro C, Di Biagio V, Di Sante F, Mariotti L, Farneti R, Sannino G (2020) The regional earth system model
RegCM-ES: evaluation of the Mediterranean climate and marine biogeochemistry. J Adv Model Earth Syst 12:e2019MS001812

Reboita MS, Reale M, da Rocha RP et al (2020) Future changes in the wintertime cyclonic activity over the CORDEX-CORE southern hemisphere domains in a multi-model approach. Clim Dyn. https://doi.org/10.1007/s00382-020-05317-z

Reboita MS, Crespo NM, Torres JA et al (2021) Future changes in winter explosive cyclones over the Southern Hemisphere domains from the CORDEX-CORE ensemble. Clim Dyn. https://doi.org/ 10.1007/s00382-021-05867-w

Rixen M et al (2005) The western Mediterranean deep water: a proxy for climate change. Geophys Res Lett 32:L12608. https://doi.org/ 10.1029/2005GL022702

Ruti P, Somot S, Giorgi F, Dubois C, Flaounas E, Obermann A, Dell'Aquila A, Pisacane G, Harzallah A, Lombardi E et al (2016) MED-CORDEX initiative for Mediterranean climate studies. BAMS https://doi.org/10.1175/Tech.repBAMS-D-14-00176.1

Sanchez-Gomez E, Somot S (2018) Impact of the internal variability on the cyclone tracks simulated by a regional climate model over the Med-CORDEX domain. Clim Dyn 51(3):1005-1021

Seager R, Liu H, Henderson N, Simpson I, Kelley C, Shaw T, Ting $M$ (2014) Causes of increasing aridification of the mediterranean region in response to rising greenhouse gases. J Clim 27(12):4655-4676

Sein DV, Mikolajewicz U, Gröger M, Fast I, Cabos W, Pinto JG et al (2015) Regionally coupled atmosphere-ocean-sea ice-marine biogeochemistry model ROM: 1. Description and VALIDATION. J Adv Model Earth Syst 7(1):268-304. https://doi.org/10.1002/ 2014MS000357

Sevault F, Somot S, Alias A, Dubois C, Lebeaupin-Brossier C, Nabat P, Adloff F, Déqué M, Decharme B (2014) A fully coupled Mediterranean regional climate system model: design and evaluation of the ocean component for the 1980-2012 period. Tellus A 66:23967. https://doi.org/10.3402/tellusa.v66.23967

Scoccimarro E, Gualdi S, Bellucci A, Sanna A, Fogli PG, Manzini E, Vichi M, Oddo P, Navarra A (2011) Effects of tropical cyclones on ocean heat transport in a high resolution coupled general circulation model. J Clim 24:4368-4384. https://doi.org/10.1175/ 2011JCLI4104.1

Scoccimarro E, Gualdi S, Villarini G, Vecchi G, Zhao M, Walsh K, Navarra A (2014) Intense precipitation events associated with landfalling tropical cyclones in response to a warmer climate and increased CO2. J Clim. https://doi.org/10.1175/ JCLI-D-14-00065.1

Shepherd TG (2019) Storyline approach to the construction of regional climate change information. Proc Royal Soc A 475(2225):20190013

Somot (2005) Modélisation climatique du bassin méditerranéen: variabilité et scénarios de changement climatique. Ph-D thesis. Université Paul Sabatier, Toulouse-France. pp 333 (in French)

Somot S, Ruti P, Ahrens B, Coppola E, Jordà G, Sannino G, Solmon F (2018) Editorial for the Med-CORDEX special issue. Clim Dyn 51(3):771-777. https://doi.org/10.1007/s00382-018-4325-x

Soto-Navarro J, Jordà G, Amores A, Cabos W, Somot S, Sevault F, Macías D, Djurdjevic V, Sannino G, Li L, Sein D (2020) Evolution of Mediterranean Sea water properties under climate change scenarios in the Med-CORDEX ensemble. Clim Dyn 54:21352165. https://doi.org/10.1007/s00382-019-05105-4

Steele M, Morley R, Ermold W (2001) PHC: a global ocean hydrography with a high quality Arctic Ocean. J Climate 14:2079-2087

Taylor KE, Stouffer RJ, Meehl GA (2012) An overview of CMIP5 and the experiment design. Bull Am Meteorol Soc 93:485-498. https://doi.org/10.1175/BAMS-D-11-00094.1

Toreti A, Xoplaki E, Maraun D, Kuglitsch FG, Wanner H, Luterbacher J (2010) Characterisation of extreme winter precipitation 
in Mediterranean coastal sites and associated anomalous atmospheric circulation patterns. Nat Hazard 10(5):1037-1050

Trigo IF (2006) Climatology and interannual variability of storm tracks in the Euro-Atlantic sector: a comparison between ERA-40 and NCEP/NCAR reanalyses. Clim Clim Dyn 26:127-143. https://doi. org/10.1007/s00382-005-0065-9

Trigo IF, Davies TD, Bigg GR (1999) Objective climatology of cyclones in the Mediterranean region. J Climate 12(6):1685-1696

Tuel A, Kang S, Eltahir EAB (2020) Understanding climate change over the southwestern Mediterranean using high-resolution simulations. Clim Dyn 56:985-1001. https://doi.org/10.1007/ s00382-020-05516-8

Ulbrich U, Lionello P, Belušic D, Jacobeit J, Knippertz P, Kuglitsch F, Leckebusch GC, Luterbacher J, Maugeri M, Maheras P, Nissen KM, Pavan V, Pinto JC, Saaroni H, Seubert S, Toreti A, Xoplaki E, Ziv B (2012) Climate of the Mediterranean: synoptic patterns, temperature, precipitation, winds, and their extremes. In: Lionello $\mathrm{P}$ (ed) The climate of the Mediterranean region. From the past to the future. Elsevier (NETHERLANDS), Amsterdam, pp 301-346 (ISBN:9780124160422)

Ulbrich U, Leckebusch GC, Grieger J, Schuster M, Akperov M, Bardin MY, Feng Y, Gulev S, Inatsu M, Keay K, Kew SF, Liberato MLR, Lionello P, Mokhov II, Neu U, Pinto JG, Raible CC, Reale M, Rudeva I, Simmonds I, Tilinina ND, Trigo IF, Ulbrich S, Wang XL, Wernli H (2013) Are greenhouse gas signals of northern hemisphere winter extra-tropical cyclone activity dependent on the identification and tracking algorithm? Meteorol Z 22:61-68. https://doi.org/10.1127/0941-2948/2013/0420

Villarini G, Lavers DA, Scoccimarro E, Zhao M, Wehner MF, Vecchi G, Knutson T (2014) Sensitivity of tropical cyclone rainfall to idealized global scale forcings. J Clim. https://doi.org/10.1175/ JCLI-D-13-00780.1

Voldoire A, Sanchez-Gomez E et al (2011) The CNRM-CM5.1 global climate model: description and basic evaluation. Clim Dyn. https://doi.org/10.1007/s00382-011-1259-y

Zappa G, Shepherd TG (2017) Storylines of atmospheric circulation change for European regional climate impact assessment. J Clim 30(16):6561-6577

Zappa G, Hawcroft MK, Shaffrey L et al (2015) Extratropical cyclones and the projected decline of winter Mediterranean precipitation in the CMIP5 models. Clim Dyn 45:1727-1738. https://doi.org/ 10.1007/s00382-014-2426-8

Zhang W, Villarini G, Scoccimarro E, Napolitano F (2020) Examining the precipitation associated with medicanes in the high-resolution ERA-5 reanalysis data. Int J Climatol. https://doi.org/10.1002/ joc.6669

Publisher's Note Springer Nature remains neutral with regard to jurisdictional claims in published maps and institutional affiliations.

\section{Authors and Affiliations}

\section{Marco Reale ${ }^{1,2}$ (D) William David Cabos Narvaez ${ }^{3}$ Leone Cavicchia ${ }^{4}$. Dario Conte ${ }^{5}$. Erika Coppola ${ }^{2}$. Emmanouil Flaounas ${ }^{6}$. Filippo Giorgi ${ }^{2}$. Silvio Gualdi ${ }^{5}$. Assaf Hochman ${ }^{7,15}$ • Laurent Li $^{8}$. Piero Lionello 9,5 . Zorica Podrascanin ${ }^{10}$. Stefano Salon ${ }^{1}$. Emilia Sanchez-Gomez ${ }^{11}$. Enrico Scoccimarro ${ }^{5}$. Dmitry V. Sein ${ }^{12,13}$. Samuel Somot ${ }^{14}$}

1 National Institute of Oceanography and Applied GeophysicsOGS, Trieste, Italy

2 Abdus Salam International Centre for Theoretical Physics, ICTP, ESP Group, Trieste, Italy

3 University of Alcala, Alcala, Spain

4 University of Melbourne, Melbourne, Australia

5 Fondazione Centro Euro-Mediterraneo Sui Cambiamenti Climatici, CMCC, Lecce, Italy

6 Institute of Oceanography, Hellenic Center for Marine Research, Athens, Greece

7 Freddy and Nadine Hermann Institute of Earth Sciences, The Hebrew University of Jerusalem (HUJI), Jerusalem, Israel

8 Laboratoire de Météorologie Dynamique, CNRS, Sorbonne Université, Paris, France

9 Department of Biological and Environmental Sciences and Technologies, DiSTeBA, University of Salento, Lecce, Italy
10 Department of Physics, Faculty of Sciences, University of Novi Sad, Novi Sad, Serbia

11 CECI, Université de Toulouse, CNRS, Cerfacs, Toulouse, France

12 Alfred Wegener Institute, Helmholtz Centre for Polar and Marine Research, Bremerhaven, Germany

13 Shirshov Institute of Oceanology, Russian Academy of Sciences, Moscow, Russia

14 CNRM (Centre National de Recherches Météorologiques), Université de Toulouse, Météo-France, CNRS, Toulouse, France

15 Department of Tropospheric Research (IMK-TRO), Institute of Meteorology and Climate Research, Karlsruhe Institute of Technology (KIT), Karlsruhe, Germany 